\title{
On the Importance of the Participation Margin for Market Fluctuations
}

\author{
Michael W.L. Elsby, \\ University of Edinburgh \\ Bart Hobijn, \\ Federal Reserve Bank of San Francisco \\ Ayşegül Şahin, \\ Federal Reserve Bank of New York
}

February 2013

Working Paper 2013-05

http://www.frbsf.org/publications/economics/papers/2013/wp2013-05.pdf

The views in this paper are solely the responsibility of the authors and should not be interpreted as reflecting the views of the Federal Reserve Bank of New York, the Federal Reserve Bank of San Francisco or the Board of Governors of the Federal Reserve System. 


\title{
On the Importance of the Participation Margin for Labor Market Fluctuations*
}

\author{
Michael W. L. Elsby \\ University of Edinburgh
}

\author{
Bart Hobijn \\ FRB San Francisco
}

Ayşegül Şahin

FRB New York

February 25, 2013

\begin{abstract}
Conventional analyses of cyclical fluctuations in the labor market ascribe a minor role to the labor force participation margin. In contrast, a flows-based decomposition of the variation in labor market stocks reveals that transitions at the participation margin account for around one-third of the cyclical variation in the unemployment rate. This result is robust to adjustments of data for spurious transitions, and for time aggregation. Inferences from conventional, stocks-based analyses of labor force participation are shown to be subject to a stock-flow fallacy, neglecting the offsetting forces of worker flows that underlie the modest cyclicality of the participation rate. A novel analysis of history dependence in worker flows demonstrates that a large part of the contribution of the participation margin can be traced to cyclical fluctuations in the composition of the unemployed by labor market attachment.
\end{abstract}

Keywords: Worker flows; unemployment; business cycles; labor force participation. JEL-codes: E24, J6.

${ }^{*}$ For helpful comments, we would like to thank Philip Jung, Richard Rogerson, Rob Shimer and Gary Solon, as well as seminar participants at Berkeley, the March 2010 Royal Economic Society Conference, Alberta, the June 2010 Recent Developments in Macroeconomics Conference in Seoul, Western Michigan, the Chicago Fed, Wisconsin, University College Dublin, INSEAD, the Central Bank of Hungary, the October 2012 Bank of England/Institute of Macroeconomics Conference, and the 3rd Ifo Conference on "Macroeconomics and Survey Data." We are very grateful to Josh Abel, Pawel Krolikowski, Joyce Kwok, and Brian Lucking for their research assistance. The views expressed in this paper are those of the authors and do not necessarily reflect those of the Federal Reserve Bank of New York, the Federal Reserve Bank of San Francisco, or the Federal Reserve System. E-mail addresses for correspondence: mike.elsby@ed.ac.uk; bart.hobijn@sf.frb.org; aysegul.sahin@ny.frb.org. 


\section{Introduction}

What is the role of the labor force participation margin in shaping fluctuations in the unemployment rate? The majority of modern theoretical and empirical research on labor market fluctuations has operated under the assumption that movements of individuals in and out of the labor force play little or no role in driving fluctuations in the unemployment rate. Recent models of labor market fluctuations, such as those informed by the search and matching tradition of Mortensen and Pissarides (1994), typically proceed under a two-state abstraction, focusing on the margin between employment and unemployment. ${ }^{1}$ Mirroring this focus, recent empirical research on labor market flows has emphasized the relative contributions of the processes of job loss and job finding in driving cyclical unemployment, neglecting the participation margin. ${ }^{2}$

Based on the cyclical behavior of labor market stocks it is tempting to conclude that movements of individuals in and out of the labor force have a small impact on unemployment variation, seemingly reinforcing the two-state abstraction of the recent literature. In particular, while there are clear, opposite cyclical patterns in rates of employment and unemployment, the labor force participation rate displays only a modest cyclicality in the United States (see, for example, Figure 1).

In this paper we take a closer look at the role of the participation margin in shaping the evolution of unemployment over the business cycle. Our analysis yields a rich set of empirical findings that challenge the conventional practice of abstracting from labor force participation in theoretical and empirical work. Our findings are as follows. First, standard estimates of worker flows among the three labor market states reveal that the moderate cyclicality of the stock of labor force participants masks substantial cyclicality in worker flows between unemployment and nonparticipation. Second, we find this channel to be quantitatively significant: Application of a novel decomposition of the variation in labor market stocks into components accounted for by underlying worker flows reveals that transitions at the participation margin account for around one-third of the cyclical variation in the unemployment rate. Third, the latter result is robust to conventional and practical adjustments of data for spurious transitions, and for time aggregation. Rather, we show that inferences from

\footnotetext{
${ }^{1}$ Theoretical papers that adopt a two-state abstraction are too numerous to cite. Exceptions to this tendency include: Alvarez and Veracierto (1999); Andolfatto and Gomme (1996); Andolfatto, Gomme, and Storer (1998); Garibaldi and Wasmer (2005); Kim (2001); Krusell, Mukoyama, Rogerson and Şahin (2010a, 2010b, 2012); Pries and Rogerson (2009); Shimer (2011); Veracierto (2008).

${ }^{2}$ Examples include: Braun, De Bock, and DiCecio (2006); Elsby, Michaels, and Solon (2009); Fujita and Ramey (2009); Hall (2005a,b); and Shimer (2012).
} 
conventional, stocks-based analyses of labor force participation are subject to a stock-flow fallacy, neglecting the offsetting forces of worker flows that underlie the modest cyclicality of the participation rate. Finally, new estimates of heterogeneity in worker flows across labor market histories reveal that an important part of the contribution of the participation margin, and therefore of unemployment fluctuations in general, can be traced to a novel channel based on cyclical shifts in the labor market attachment composition of the unemployed.

The starting point for our analysis is the standard data source for the study of worker flows in the United States: the longitudinally-linked monthly Current Population Survey (CPS) microdata, known as the "gross flows". These data have been analyzed extensively in prior empirical work on labor market dynamics. ${ }^{3}$ In Section 2 we update these estimates and review their basic cyclical properties. There we confirm the countercyclicality of the employment-to-unemployment transition probability, and the corresponding procyclicality of the unemployment-to-employment transition probability, that have been widely documented in previous literature. But, we also highlight an often-neglected feature of the gross flows estimates that are crucial to our findings: During recessions, unemployed workers are less likely to flow out of the labor force, and nonparticipants are more likely to flow into unemployment. These two forces both are likely to contribute to the rise in the level of unemployment that accompanies recessions. The remainder of this paper investigates the robustness of this observation, provides an accounting framework that allows one to quantify the magnitude of this channel, and explores potential explanations for this phenomenon.

A particular issue that arises when one uses the gross flows data is that they are thought to be particularly susceptible to classification errors in recorded labor market status (National Commission on Employment and Unemployment Statistics, 1979). While such errors may largely cancel in measured labor market stocks, they can accumulate in estimates of worker flows, leading to spurious measured transitions. Previous research has found these errors to be substantial, especially for transitions between unemployment and nonparticipation (see, for example, Abowd and Zellner, 1985; Poterba and Summers, 1986; and Chua and Fuller, 1987).

In section 3, we take this possibility seriously and examine whether adjustments for misclassification errors have an impact on the cyclicality of worker flows at the participation margin. We consider two approaches. First, following Blanchard and Diamond (1990), we apply Abowd and Zellner's (1985) estimates of misclassification probabilities inferred from

\footnotetext{
${ }^{3}$ Early examples include Kaitz (1970), Perry (1972), and Marston (1976). More recent analyses include Blanchard and Diamond (1990), Fujita and Ramey (2006), and Shimer (2012).
} 
CPS reinterview surveys to adjust the gross flows estimates for spurious transitions. As noted in prior literature, this adjustment substantially reduces the estimated flows, especially those that involve transitions in and out of the labor force. We further show that, even though these estimates of classification errors are assumed to be time-invariant, they may nevertheless impart a countercyclical bias in gross flows estimates of the number of workers transitioning between unemployment and nonparticipation. Intuitively, times of recession are accompanied by a rise in the number of nonemployed individuals at risk of being misclassified. Consistent with this intuition, the countercyclicality of the inflow rate into unemployment from nonparticipation is shaded down in the adjusted data, and the rate of outflow of unemployed workers into nonparticipation remains prominently procyclical.

The estimates of classification errors reported in Abowd and Zellner (1985) are inferred under a particular assumption about the nature of these errors-specifically that they are independently and identically distributed across time. For this reason, we also examine a second, more practical adjustment of the data. This exploits the fact that the rotation structure of the CPS makes it possible to match individual responses across four consecutive months, albeit for a more restricted sample of respondents. Using this smaller sample, we assess the effect of recoding sequences of recorded labor market states to eliminate high-frequency reversals of transitions between unemployment and nonparticipation. A prominent example of the latter are consecutive monthly transitions from nonparticipation to unemployment and then back to nonparticipation again. Since our method involves removing these $N U N$ sequences, we sometimes will refer to these adjusted flows as "deNUNified" flows. Although not a definitive adjustment for classification error, the elimination of such sequences of worker flows provides a sense of whether the cyclicality of flows between unemployment and nonparticipation is particularly driven by such high frequency reversals of flows in and out of the labor force. ${ }^{4}$

A striking feature of the results of this more practical recoding approach is that the adjusted flows line up closely with those implied by the Abowd and Zellner (1985) correction. This is the case despite the fact that the two adjustments are based on very different motivations: The Abowd and Zellner correction is inferred from data on resolved labor force status from CPS reinterview surveys; the de $N U N$ ified flows simply iron out reversals of a set of worker transitions. What emerges from this analysis is that, while the countercyclicality of the nonparticipation-to-unemployment rate is diminished by both conventional and practical

\footnotetext{
${ }^{4}$ In his analysis of the effects of Unemployment Insurance (UI) extensions on unemployment exit rates, Rothstein (2011) implements a similar adjustment for similar reasons.
} 
adjustments for classification error, the procyclicality of the rate of outflow of unemployed workers into nonparticipation appears to be a robust feature of the dynamics of the labor market in the United States.

In addition to classification errors that tend to inflate estimates of worker transition rates, the gross flows data also are subject to an offsetting bias that leads to an understatement of flows. In particular, due to the discrete monthly nature of the CPS, measured transition probabilities are subject to a time aggregation problem - they may miss multiple transitions that occur between consecutive monthly surveys - and thus may not accurately reflect the underlying flows (Darby, Haltiwanger and Plant, 1985; Shimer, 2012). In section 4, we implement an analytical correction for time aggregation that can be applied to estimates of worker flows among arbitrarily many labor force states, such as the usual three. ${ }^{5}$ We apply this methodology to infer a set of estimates of the underlying continuous-time flow hazards among employment, unemployment and nonparticipation, both for the raw gross flows estimates, as well as those adjusted for classification error. These estimates suggest that time aggregation bias has a substantial effect on the measured levels of worker flowsstandard gross flows measures of transition probabilities are estimated to miss 15 to 30 percent of the underlying flows. However, we find that the cyclical behavior of the estimated flow hazards, including those between unemployment and nonparticipation, is nonetheless preserved.

Taking these estimates of flow hazards as our data, in Section 5 we devise a novel decomposition of the time-series variation in each of the labor market states into components accounted for by each of the associated worker flow hazards. The decomposition exploits a partial-adjustment representation of the dynamics of labor market stocks that allows one to express the change in each of the stocks as a distributed lag of current and past changes in the flow hazards among labor market states. This in turn motivates a simple decomposition of variance that allows one to compute the fraction of variance in each labor force state accounted for by variation in each flow hazard.

Our approach makes important progress on a number of dimensions relative to other recent work that has analyzed the role of worker flows. First, following Shimer (2012), many papers have examined the consequences for flow-steady-state unemployment of holding constant one or more of the worker flow hazards (Gomes, 2012; King, 2011; Kudlyak

\footnotetext{
${ }^{5}$ Since our work on early versions of this paper, we learned of concurrent work by Shimer $(2011,2012)$ that develops the same time aggregation correction. This correction already has been applied in other recent work on worker flows - see, for example, Barnichon and Figura (2012).
} 
and Schwartzman, 2012). Our approach instead provides an explicit analytical decomposition that accounts both for the nonlinear relationship between flows and stocks, as well as the out-of-steady-state transmission of past movements in worker flows. Second, since the earlier work of Petrongolo and Pissarides (2008), many papers have combined together the contributions of one or more of the flows in and out of the labor force (Barnichon and Figura, 2012; Elsby, Smith and Wadsworth, 2011; Smith, 2011). In constrast, our approach infers individual contributions for all of the underlying worker flows. Third, due to the generality of our approach, it can be used to investigate the flow origins of variation in any combination of labor market stocks, such as the participation rate. We show that the latter provides an important perspective on why decompositions based respectively on stocks and flows yield divergent results on the role of the participation margin.

We apply this decomposition to our estimates of worker flows, both with and without adjustments for classification error. The results of this exercise inform a key result of the paper: that the participation margin accounts for a substantial fraction, around one-third, of the rise in unemployment during recessions in the United States. Of particular importance is the procyclicality of the flow rate from unemployment to nonparticipation, which we find accounts for the majority of the contribution of the participation margin. In addition, we find that the contribution of the participation margin remains substantial even after adjustments for classification error. Thus, the cyclicality of flows between unemployment and nonparticipation that we highlight has an important quantitative impact on the evolution of the unemployment rate.

As discussed in the opening paragraphs of this paper, our finding of a significant role for the participation margin in driving unemployment fluctuations challenges conventional wisdom on the topic. The latter instead holds that the modest reductions in labor force participation that accompany recessions in fact serve to reduce slightly the associated rise in unemployment. In section 6, we explain why such reasoning is an example of a stock-flow fallacy. We show that it is important to realize that the cyclical behavior of the labor force participation rate is itself the outcome of subtle interactions of movements in worker flow rates, just like the unemployment rate.

We illustrate this point by exploiting a virtue of our flows-based variance decomposition, namely that it can be applied to any combination of labor market stocks, in particular the participation rate. Using a set of examples, we show that much of the variation in labor force participation can in fact be traced to movements in flows between employment and nonparticipation. Such flows have only an indirect effect on the unemployment rate, yet an 
analysis of labor market stocks would incorrectly ascribe to this variation an unemploymentreducing role in times of recession.

The message of this paper, then, is that a complete understanding of fluctuations in unemployment in the United States requires an understanding of the apparent cyclical movements in worker flows at the participation margin. In section 7 of the paper, we assess a number of hypotheses that potentially can account for these observations. Our analysis identifies one particularly fruitful avenue of research toward this end. We propose and quantify a novel hypothesis for procyclical behavior of the rate of outflow of unemployed workers to nonparticipation, based on cyclical shifts in the degree to which unemployed workers are attached to the labor market. Using CPS microdata matched across all available months in the sample, we provide new estimates of worker flows conditional on past labor market status, defined as status one year prior to the CPS survey. Quite sensibly, we find that unemployed individuals that were employed in the past are much less likely to exit the labor force than their nonemployed counterparts. Importantly, during recessions, the composition of the unemployment pool shifts towards workers who are more attached to the labor market, in particular male, prime-aged individuals who were employed in the past. The latter is consistent with the wave of job loss that occurs at the onset of downturns in the United States. We find that this compositional shift along just these few dimensions accounts for a large part-around three-quarters - of the recessionary decline in the rate of exit of unemployed workers from the labor force since the late 1970s. ${ }^{6}$ Since the latter accounts for the majority of the contribution of the participation margin, this is an important result.

Section 7 also investigates the underlying reasons for the observed countercyclicality of the flow rate from nonparticipation to unemployment. As noted above, the presence of classification errors can induce a countercyclical bias in these worker flows. Consistent with this, we find that adjustments for these errors do reduce the estimated contribution of labor force entry to unemployment cyclicality. However, the magnitude of the effect depends on the particular adjustment for misclassification. Our discussion further considers the potential

\footnotetext{
${ }^{6}$ This finding contrasts with those of Baker (1992) and Shimer (2012), who investigate the role of compositional shifts on the total rate of outflow from unemployment, and find only small effects. Our own analysis suggests that this difference can be traced to two factors: First, a novel aspect of our analysis is that it adjusts additionally for composition across past labor market status, a dimension that we find to be especially important. Second, we emphasize composition effects on the outflow rate to nonparticipation, which is just one part of the total outflow rate analyzed by Baker and Shimer. Interestingly, we find offsetting effects of composition on the other component, outflows to employment. This, of course, is consistent with the notion that the composition of the unemployment pool shifts in recessions towards those who are relatively more attached to the labor market.
} 
role of the added worker effect - the idea that nonparticipant partners begin searching in times of recession to replace lost household income. Challenging this view, we find that the countercyclicality of the flows from nonparticipation to unemployment is not dominated by the labor force entry of prime-aged women, the group typically associated with the added worker effect. Rather, the cyclicality of labor force entry appears to be broad-based among young and prime-aged men and women.

In the closing section of the paper, we reflect on the implications of our results for future research. At a basic level, our findings emphasize the importance of the interaction of labor supply and unemployment for an understanding of labor market fluctuations. But, in addition, our empirical results also inform the nature of the economics behind this interaction. The importance of labor market attachment that we uncover highlights the role of worker heterogeneity, and the particular salience of marginal individuals that arises in such an environment, for understanding the participation margin. Furthermore, our results caution against the view that the presence of such marginally-attached individuals undermines the economic significance of cyclical movements in the unemployment rate. To the contrary, we find that the degree of labor market attachment in the jobless pool varies with the cycle, rising systematically during downturns. Our results therefore underscore the particular importance of unemployment in times of recession.

\section{Data on labor market flows}

The data we use are the "gross flows" data from the Current Population Survey (CPS). These measures of worker flows are obtained by exploiting a rotating-panel element in the CPS sample design. Addresses selected into the survey remain in the sample for four consecutive months, rotate out for eight months, and then rotate back in again for a further four months. A consequence is that, in any given month, the CPS is comprised of eight "rotation groups," six of which will be surveyed again in the subsequent month. In principle, then, a maximum of three-quarters of the sample in a given month can be linked longitudinally to their responses one month later. In practice, however, it is possible to match approximately two-thirds of the CPS sample across consecutive months due to non-response, changes of residence and so on.

Using these longitudinally-linked microdata, it is straightforward to estimate worker flows and their associated transition probabilities. For example, the probability that an unemployed worker finds a job and is employed one month later can be computed simply as the 
fraction of the unemployed in a given month who subsequently report that they are employed in the next month's survey. Using this method, one can compute monthly flow transition probabilities among employment, unemployment and nonparticipation for each month of available data.

Measures of worker flows based on this approach have been made available from a number of sources. Data for February 1990 onwards are posted on the Bureau of Labor Statistics website. Shimer (2012) has computed analogous measures using CPS microdata from January 1976. Data from June 1967 to December 1975 have been tabulated by Joe Ritter and made available by Hoyt Bleakley.

These measures have become the standard source for estimating worker flows among labor force states. They are the basis of a long line of research on unemployment flows, and have informed much of what we know about labor market dynamics (see, among many others, Kaitz, 1970; Perry, 1972; Marston, 1976; Blanchard and Diamond, 1990; Fujita and Ramey, 2006; and Shimer, 2012). While these data are known to be subject to a number of drawbacks that are the subject of the ensuing sections, it is instructive first to summarize the basic cyclical properties of worker flows in the gross flows data. The "unadjusted" series in Figure 2 plot the raw gross flows transition probabilities between employment, unemployment and nonparticipation. There are clear, systematic empirical regularities in the behavior of these measures over the business cycle. Among these, a particularly well-emphasized observation is the notable countercyclicality of the employmentto-unemployment probability, and the prominent procyclicality of the unemployment-toemployment probability, a feature confirmed in panels (a) and (b) of Figure 2. Clearly, both of these contribute to the cyclicality of the unemployment rate.

Considerably less emphasis has been given to fluctuations in flow probabilities between unemployment and nonparticipation over the business cycle, however. Panels (c) and (d) of Figure 2 reveal that rates of inflow to unemployment from nonparticipation rise substantially in recessions, while rates of outflow to nonparticipation decline substantially. By the same token, these flows in and out of the labor force also must contribute to the rise in unemployment that accompanies recessions in the United States. The magnitude of this contribution and its robustness are the focus of the remainder of the paper. 


\section{Adjustments for classification error}

A drawback of the gross flows estimates is that they are sensitive to classification errors in recorded labor market states, which may lead to spurious measured transitions. For example, imagine a respondent who is in fact unemployed for three consecutive surveys, but who is misclassified as out of the labor force in the second survey. In this example, we would observe two spurious measured transitions - from unemployment to nonparticipation and vice versa. Estimates of classification errors suggest that spurious transitions are particularly important for such transitions between unemployment and nonparticipation (Abowd and Zellner, 1985; Poterba and Summers, 1986).

Because these transitions between unemployment and nonparticipation are the particular focus of our study, we take the potential effects of such classification errors seriously. In order to consider whether our results are affected by these errors, we examine the effect of two specific adjustments of the data. In the remainder of this section we introduce these two adjustment methods and document their effects on the time series behavior of labor market stocks and flows.

\subsection{Abowd and Zellner (1985) correction}

The first adjustment we consider is based on a literature that has sought to estimate the magnitude of classification errors in recorded labor market status using data from a subsample of the CPS (around one-thirtieth of the overall sample) that is reinterviewed each month (see, for example, Abowd and Zellner, 1985; Poterba and Summers, 1986; and Chua and Fuller, 1987). Denoting the measured stocks of employed, unemployed and nonparticipants

respectively as $\widehat{E}, \widehat{U}$, and $\widehat{N}$, these studies assume the following relation between measured stocks and their "true" counterparts $E, U$, and $N$ :

$$
\left[\begin{array}{c}
\widehat{E} \\
\widehat{U} \\
\widehat{N}
\end{array}\right]_{t}=\underbrace{\left[\begin{array}{ccc}
1-\varepsilon_{E U}-\varepsilon_{E N} & \varepsilon_{U E} & \varepsilon_{N E} \\
\varepsilon_{E U} & 1-\varepsilon_{U E}-\varepsilon_{U N} & \varepsilon_{N U} \\
\varepsilon_{E N} & \varepsilon_{U N} & 1-\varepsilon_{N E}-\varepsilon_{N E}
\end{array}\right]}_{\mathbf{E}}\left[\begin{array}{c}
E \\
U \\
N
\end{array}\right]_{t}
$$

where, $\varepsilon_{i j}$ is the probability that an individual with true labor market state $i$ is recorded as measured state $j$.

Estimates of the elements of the matrix of classification error probabilities $\mathbf{E}$ are based on a series of CPS reinterview surveys in which CPS respondents were contacted for a follow-up 
interview to check the validity of their original responses. Table 1 reproduces the estimate of $\mathbf{E}$ from Abowd and Zellner (1985, Table 6). It can be seen that the most common classification error relates to individuals counted as nonparticipants whose "resolved" status is unemployed. This is true for approximately 10 percent of persons who were determined to be unemployed upon reinterview.

These estimates of $\mathbf{E}$ allow one to infer estimates of the underlying corrected worker flows from the raw measured gross flows. Specifically, if we denote the number (as opposed to the transition probabilities) of individuals flowing from state $i$ in month $t-1$ to state $j$ in month $t$ by $i j_{t}$, and the associated matrix of these flows by

$$
\mathbf{N}_{t}=\left[\begin{array}{ccc}
E E & U E & N E \\
E U & U U & N U \\
E N & U N & N N
\end{array}\right]_{t}
$$

then Poterba and Summers (1986) show that measured flows, $\widehat{\mathbf{N}}_{t}$, can be related to their true counterparts $\mathbf{N}_{t}$ according to the relation $\widehat{\mathbf{N}}_{t}=\mathbf{E N}_{t} \mathbf{E}^{\prime}$. One may then infer the matrix of corrected flows simply by inverting this relation to obtain

$$
\mathbf{N}_{t}=\mathbf{E}^{-1} \widehat{\mathbf{N}}_{t}\left(\mathbf{E}^{-1}\right)^{\prime}
$$

An implicit assumption that underlies this adjustment is that classification errors are time-invariant. A priori, then, it would seem unlikely that such misclassification could explain the cyclical fluctuations in these flows we document above. We argue that such a conclusion would be premature. To see why, it is helpful to consider a simple special case in which classification errors exist only between unemployment and nonparticipation - that is, $\varepsilon_{i j}=0$ for all $i j \notin\{U N, N U\}$. For small $\varepsilon_{U N}$ and $\varepsilon_{N U}$, we show in the Appendix that measured flows between unemployment and nonparticipation can be related to error-free flows according to the simple approximations:

$$
\begin{aligned}
& \widehat{U N}_{t} \approx\left(1-\varepsilon_{U N}-\varepsilon_{N U}\right) U N_{t}+\varepsilon_{U N} U U_{t}+\varepsilon_{N U} N N_{t}, \text { and } \\
& \widehat{N U}_{t} \approx\left(1-\varepsilon_{U N}-\varepsilon_{N U}\right) N U_{t}+\varepsilon_{U N} U U_{t}+\varepsilon_{N U} N N_{t} .
\end{aligned}
$$

The first terms in these expressions capture respectively the fraction of true flows that show up in measured transitions. The subsequent terms capture spurious transitions driven by classification errors. 
Equation (4) highlights why even time-invariant classification errors can imply a bias in measured flows that varies over the cycle. The key is that the number of individuals who remain unemployed $U U_{t}$ rises substantially in recessions as the stock of unemployed workers itself rises. As a result, this imparts a countercyclical bias in measured transitions between unemployment and nonparticipation, $U N_{t}$ and $N U_{t}$. The intuition is simple: During a recession, there are more nonemployed individuals at risk of being misclassified.

\subsection{Recoding of unemployment-nonparticipation cyclers}

The Abowd-Zellner correction for classification errors summarized has two potential shortcomings. First of all, it is based on data from past reinterview surveys. ${ }^{7}$ Second, it relies on a maintained assumption that measurement errors are time-invariant. ${ }^{8}$ We therefore examine an alternative adjustment of measured transitions which, for reasons that will become clear, we sometimes will refer to as deNUNified flows. This adjustment takes a more practical approach: It identifies individuals whose measured labor market state cycles between unemployment and nonparticipation from month to month, and assesses the effect of omitting such transitions on the cyclical properties of the associated flows.

In order to identify such transitions, it is necessary to match an individual's labor market status across more than just two months. The rotation structure of the CPS is such that each household is surveyed for two sets of four consecutive months, with an intervening eightmonth hiatus. Thus, the CPS allows one to identify an individual's labor market status for a maximum of four successive months. These are the data that we use for our recoding procedure.

Our approach is first to isolate sequences of transitions that involve the reversal of a transition from unemployment to nonparticipation and vice versa. We denote a sequence of transitions from unemployment to nonparticipation to unemployment as $U N U \mathrm{~s}$, and analogously $N$-to- $U$-to- $N$ sequences as $N U N$ s. We then examine the effects of recoding the data to eliminate these transition reversals - hence "de $N U N$ ified" flows. Table 2 summarizes the combinations of flow sequences that are recoded in this way.

\footnotetext{
${ }^{7}$ Unfortunately, CPS reinterview survey data are no longer being released by the BLS. It is therefore not possible to update the estimates of $\mathbf{E}$ in Table 1.

${ }^{8}$ That said, Abowd and Zellner (1985) do present adjusted estimates of worker flows based on estimates of classification error probabilities computed at a quarterly frequency for the years 1977 to 1982 (see their Figures 1 through 5 and the surrounding discussion). They suggest that there is little evidence of time variation in the magnitude of adjustment, suggesting that their classification error estimates do not vary much over their sample period.
} 
The goal of this exercise is not to provide a definitive correction of labor market flows for classification errors: The approach inevitably will miss some spurious transitions between unemployment and nonparticipation, and will purge some genuine transitions. The goal is rather to investigate whether the recoding of transitions that are more likely to reflect measurement error has a significant impact on the cyclicality of flow transitions between unemployment and nonparticipation. This approach complements the correction in the previous subsection in the sense that it relies neither on the use of reinterview data from the past nor on an assumption of time-invariant classification errors.

\subsection{Stocks and flows adjusted for classification error}

Figure 1 plots the published unemployment and participation rates together with those implied by the Abowd and Zellner (1985, AZ) correction and the deNUNified flows. The left and right panels respectively depict the time series for the associated unemployment rates and labor force participation rates.

We find that both adjustments for classification errors imply quite small adjustments of labor market stocks. The reason relates to the intuition that classification errors will tend to cancel out in the cross section (see, for example, National Commission on Employment and Unemployment Statistics, 1979). In accordance with this intuition, we find that the number of $N U N$ s and $U N U$ s tend almost to offset one another, so that our recoding procedure leaves the implied stocks almost unchanged. The AZ correction induces a modest adjustment to the levels of the unemployment and participation rates. This arises because the most common error is the misclassification of someone who is unemployed as being out of the labor force (see Table 1). As a result, the correction reclassifies a number of people from nonparticipation into unemployment, thus raising slightly both the unemployment rate and the participation rate. In addition, Figure 1 suggests that both adjustments have a very small effect on the cyclicality of labor market stocks. ${ }^{9}$

In contrast, we find that estimated worker flows are more sensitive to the presence of classification errors, consistent with the intuition above. The effects of each adjustment for classification error on estimated worker flows are illustrated in Figure 2. This plots the estimated transition probabilities $p_{i j_{t}} \equiv i j_{t} / i_{t-1}$ for $i, j \in\{E, U, N\}$, that have been

\footnotetext{
${ }^{9}$ Recent work by Feng and $\mathrm{Hu}(2012)$ applies a different classification error adjustment that implies larger increases in the unemployment rate and a smaller rise in the participation rate. The directions of the adjustments are similar though and their method does not yield adjusted gross flows estimates that we use for our analysis.
} 
adjusted for classification errors, together with their unadjusted counterparts for reference. The AZ-adjusted flows are obtained by applying the adjustment in equation (3) to the gross flows data described above in Section 2. The de $N U N$ ified flows instead are based on CPS microdata in which individuals' outcomes have been matched over all months in sample.

In keeping with prior literature, for all plotted series we implement a correction for margin error that restricts the estimates of worker flows to be consistent with the evolution of the corresponding labor market stocks depicted in Figure $1 .{ }^{10}$ Our approach is similar to that employed by Poterba and Summers (1986), and solves for the set of stock-consistent transition probabilities that minimizes the weighted sum of squares of the margin-error adjustments, and is described in detail in the Appendix. In practice, however, we find that the margin-error adjustment has a very small effect on the estimated transition probabilities.

Consistent with the notion that classification errors can accumulate in estimated flows leading to spurious estimated transitions, Figure 2 reveals that the adjusted flows lie systematically below their unadjusted counterparts. As noted in prior literature, flows in and out of the labor force particularly are affected. Transition rates between employment and nonparticipation are approximately halved, while those between unemployment and nonparticipation are adjusted down by around one third.

Interestingly, the cyclicality of rates of transition between $U$ and $N$ also appears to be affected in a manner consistent with the intuition of equation (4). While the nonparticipationto-unemployment transition rate remains countercyclical, its fluctuations are seen to be less volatile than in the raw gross flows data. In contrast, the adjusted unemploymentto-nonparticipation rate retains its procyclicality. Both of these observations dovetail with the logic above that classification errors can lead to a countercyclical bias in flows between unemployment and nonparticipation.

Figure 2 also illustrates the impact of the adjustment for classification error based on the recoding of unemployment-nonparticipation cyclers. Unsurprisingly, the adjustment has little effect on flow transition rates between employment and unemployment, and employment and nonparticipation. The time series for these flow hazards differ slightly from those implied by the raw gross flows because the adjusted flows are based on the smaller sample

\footnotetext{
${ }^{10}$ Margin error can arise for a number of reasons. First, we ignore movements in and out of the working-age population, such as those who turn 16, die, immigrate, emigrate and so on, that are classified as "other" in the BLS gross flows data. In addition, it is possible that attrition of households from our matched CPS samples is not random with respect to labor force status. For both these reasons, implied changes in labor market stocks in our matched samples may not necessarily replicate changes in the published stocks. Our finding, however, is that there is only a small discrepancy between implied and published changes in stocks.
} 
of households that can be matched across four consecutive months (rather than just two).

A striking aspect of Figure 2, however, is that the de $N U N$ ified transition rates between unemployment and nonparticipation correspond very closely to the adjusted flows based on the Abowd and Zellner (1985) estimates of time-invariant classification errors. Note that there is no mechanical reason to expect this: The AZ adjustment is based on error probabilities implied by resolved labor force status from reinterview data; the recoding approach simply unwinds reversals of transitions between unemployment and nonparticipation. The correspondence between the two adjustments holds both in terms of the levels of these flow hazards, as well as their cyclicality. Both the rates of inflow to and outflow from unemployment on the participation margin are reduced by around one-third. As in the AZ-adjusted data, inflows into unemployment from out of the labor force are weakly countercyclical. Importantly, the rate at which the unemployed flow out of the labor force continues to fall substantially in times of recession.

\section{Adjustments for temporal aggregation}

Due to the monthly frequency of the CPS data, the gross flows provide us only with a series of snapshots of an individual's labor force status observed at discrete points in time. In practice, however, a person may make multiple transitions between consecutive surveys. For this reason, the gross flows estimates will not provide an accurate picture of the underlying flows - they will miss some transitions and incorrectly include others.

To see this, imagine an individual who is recorded as a nonparticipant in one month and as employed in the next month. In principle, there is an infinity of possible (though not equally-probable) paths that would yield this observation in discrete-time data. For example, the person could have flowed from nonparticipation to unemployment, and then from unemployment to employment. In that case, the discrete-time data would miss the latter two transitions, and would incorrectly ascribe them to a single employment to nonparticipation flow.

This temporal aggregation problem was noted by Darby, Haltiwanger and Plant (1985), and Shimer $(2011,2012)$ has provided a correction for this bias, which we summarize here. The task is to back out from estimates of the discrete-time transition probabilities $p_{i j}$ corresponding estimates of the underlying instantaneous flow hazard rates, which we shall denote $f_{i j}$. In the Appendix, we show how the mapping between these takes a simple analytical form. The key point is that the underlying continuous-time flows must replicate the observed 
path of labor market stocks each period. This implies a tight link between the dynamics and steady states of the observed discrete-time flows $p_{i j}$, and their notional continuous-time counterparts $f_{i j}$. This mapping takes the convenient form of an eigendecomposition, and thereby allows one to infer all of the underlying flow hazards, $f_{i j}{ }^{11}$

The impact of temporal aggregation bias on estimated worker flow probabilities can be seen in Figure 3. This plots the associated one-month transition probabilities implied by the time-aggregation correction, $1-e^{-f_{i j_{t}}}$. Consistent with the intuitive discussion at the beginning of this section, Figure 3 reveals that temporal aggregation in the raw gross flows misses some transitions, and incorrectly adds others. Specifically, the correction implies that the raw gross flows miss around 30 percent of inflows into unemployment, and 15 percent of outflows from unemployment to both employment and nonparticipation. In contrast, temporal aggregation in the raw gross flows leads to a slight overstatement of transitions between employment and nonparticipation.

The intuition for these results can be traced in large part to the magnitude of the probability of exiting unemployment in the United States. Figure 3 shows that unemployed individuals flow into both employment and nonparticipation with an average probability of around 25 percent over the course of a month. As a result, the likelihood that an individual who flows into unemployment between CPS surveys exits unemployment prior to the next month's survey is nontrivial. Consequently, the raw gross flows will understate transitions in and out of unemployment. For the same reason, the overstatement of transitions between employment and nonparticipation in the gross flows data arises because an individual is more likely to experience an intervening unemployment spell when transitioning between these two states.

Aside from the effect of temporal aggregation on the estimated levels of worker flows, a notable feature of the adjusted flows in Figure 3 is that the cyclical properties of the corrected series are qualitatively unchanged. Importantly for the focus of this paper, the rate of outflow from unemployment to nonparticipation continues to fall during recessionary episodes after adjusting for temporal aggregation.

\footnotetext{
${ }^{11} \mathrm{~A}$ drawback of the approach is that it assumes that there is a contemporaneous mapping between an individual's labor market activities - working, searching, not searching - and their recorded labor market states - employment, unemployment and nonparticipation. In practice, there is a dynamic mapping between activities and recorded states. For example, to be recorded as unemployed, a respondent must have looked for work during the last month under the CPS definition. It is an important topic for future research to disentangle these more subtle time aggregation issues.
} 


\section{Measuring the role of the participation margin}

With measures of the instantaneous transition rates $f_{i j}$ in hand, we can use them to inform a decomposition of the time-series variance of each of the labor market stocks into parts accounted for by each of the respective flow hazards. In this section, we devise such a decomposition using analytical approximations to a partial-adjustment representation of labor market dynamics. We then apply this decomposition to the estimates of the flow hazards described above.

\subsection{A three-state decomposition of unemployment fluctuations}

In order to motivate our decomposition of variance, it is helpful first to formalize the mapping between the labor force stocks and flows. The latter takes the form of a simple discrete-time Markov chain,

$$
\left[\begin{array}{c}
E \\
U \\
N
\end{array}\right]_{t}=\left[\begin{array}{ccc}
1-p_{E U}-p_{E N} & p_{U E} & p_{N E} \\
p_{E U} & 1-p_{U E}-p_{U N} & p_{N U} \\
p_{E N} & p_{U N} & 1-p_{N E}-p_{N U}
\end{array}\right]_{t}\left[\begin{array}{c}
E \\
U \\
N
\end{array}\right]_{t-1}
$$

This in turn can be simplified further by normalizing labor market stocks by the civilian non-institutional working-age population, $E_{t}+U_{t}+N_{t} \equiv 1$ for all $t$, so that $E_{t}$, $U_{t}$ and $N_{t}$ are to be interpreted as shares of the population. ${ }^{12}$ It follows that the three-equation system (5) can be rewritten as a two-dimensional system of the form

$$
\underbrace{\left[\begin{array}{c}
E \\
U
\end{array}\right]_{t}}_{\mathbf{s}_{t}}=\underbrace{\left[\begin{array}{cc}
1-p_{E U}-p_{E N}-p_{N E} & p_{U E}-p_{N E} \\
p_{E U}-p_{N U} & 1-p_{U E}-p_{U N}-p_{N U}
\end{array}\right]_{t}}_{\widetilde{\mathbf{P}}_{t}} \underbrace{\left[\begin{array}{c}
E \\
U
\end{array}\right]_{t-1}}_{\mathbf{s}_{t-1}}+\underbrace{\left[\begin{array}{c}
p_{N E} \\
p_{N U}
\end{array}\right]_{t}}_{\mathbf{q}_{t}}
$$

We denote the flow steady state of this Markov chain by $\overline{\mathbf{s}}_{t}=\left(\mathbf{I}-\widetilde{\mathbf{P}}_{t}\right)^{-1} \mathbf{q}_{t}$.

As in the two-state case described in Elsby, Hobijn, and Şahin (forthcoming), changes over time in the flow hazards $f_{i j}$ shift the discrete-time transition probabilities $p_{i j}$, as well as the steady state that the labor market is converging to, $\overline{\mathbf{s}}_{t}$. It is through this chain of events that changes in the underlying flows affect the path of employment and unemployment over

\footnotetext{
${ }^{12}$ As mentioned in footnote 10, initially we ignore flows in and out of the population, and then make a small correction for margin error. Thus, implied labor market stocks in our flow analysis do in fact add up to the working-age population, as assumed in equation (6).
} 
time. We show in the Appendix that this intuition can be formalized in the form of the following partial-adjustment representation:

$$
\Delta \mathbf{s}_{t}=\mathbf{A}_{t} \Delta \overline{\mathbf{s}}_{t}+\mathbf{B}_{t} \Delta \mathbf{s}_{t-1}
$$

where $\mathbf{A}_{t}=\left(\mathbf{I}-\widetilde{\mathbf{P}}_{t}\right)$ and $\mathbf{B}_{t}=\left(\mathbf{I}-\widetilde{\mathbf{P}}_{t}\right) \widetilde{\mathbf{P}}_{t-1}\left(\mathbf{I}-\widetilde{\mathbf{P}}_{t-1}\right)^{-1}$. The first term in (7) captures the changes in labor market stocks that are driven by contemporaneous changes in the flow transition rates which shift the flow steady state, $\overline{\mathbf{s}}_{t}$. The second term in equation (7) summarizes the transmission of past changes in transition rates onto the current labor market state.

This partial adjustment representation can be used to motivate a decomposition of variance for the change in labor market stocks over time, $\Delta s_{t}$. To see how, note first that one can iterate backward on equation (7) to express $\Delta \mathbf{s}_{t}$ as a distributed lag of past changes in the steady-state labor market stocks $\Delta \overline{\mathbf{s}}_{t}$,

$$
\Delta \mathbf{s}_{t}=\sum_{k=0}^{t-1} \mathbf{C}_{k, t} \Delta \overline{\mathbf{s}}_{t-k}+\mathbf{D}_{t} \Delta \mathbf{s}_{0}
$$

where $\mathbf{C}_{k, t}=\left(\prod_{n=0}^{s-1} \mathbf{B}_{t-n}\right) \mathbf{A}_{t-k}$ and $\mathbf{D}_{t}=\prod_{k=0}^{t-1} \mathbf{B}_{t-k}$, and $\Delta \mathbf{s}_{0}$ is the change in labor market stocks in the first period of available data.

As we noted above, changes in the flow hazards $f_{i j}$ shape the present and future evolution of $\Delta \mathbf{s}_{t}$ by shifting its flow-steady-state counterpart, $\Delta \overline{\mathbf{s}}_{t}$. Thus, to link changes in labor market stocks to changes in the flow hazards, we take a first-order approximation to the change in the steady-state labor market stocks,

$$
\Delta \overline{\mathbf{s}}_{t} \approx \sum_{i \neq j} \frac{\partial \overline{\mathbf{s}}_{t}}{\partial f_{i j_{t}}} \Delta f_{i j_{t}},
$$

where the approximation has been taken around the lagged flow hazard rates, $f_{i j_{t-1}}$. To compute the derivatives in equation (9), note that we can write the continuous-time analogue to the reduced-state Markov chain in (6) as

$$
\dot{\mathbf{s}}_{t}=\underbrace{\left[\begin{array}{cc}
-f_{E U}-f_{E N}-f_{N E} & f_{U E}-f_{N E} \\
f_{E U}-f_{N U} & -f_{U E}-f_{U N}-f_{N U}
\end{array}\right]_{t}}_{\widetilde{\mathbf{F}}_{t}} \mathbf{s}_{t}+\underbrace{\left[\begin{array}{c}
f_{N E} \\
f_{N U}
\end{array}\right]_{t}}_{\mathbf{g}_{t}} .
$$

It follows that the flow steady state of the system can be rewritten as $\overline{\mathbf{s}}_{t}=-\widetilde{\mathbf{F}}^{-1} \mathbf{g}_{t}$. Using 
this, the associated derivatives in equation (9) are straightforward to compute analytically.

Piecing these components together yields the following decomposition of variance:

$$
\operatorname{var}\left(\Delta \mathbf{s}_{t}\right) \approx \sum_{i \neq j} \operatorname{cov}\left(\Delta \mathbf{s}_{t}, \sum_{k=0}^{t-1} \mathbf{C}_{k, t} \frac{\partial \overline{\mathbf{s}}_{t-k}}{\partial f_{i j_{t-k}}} \Delta f_{i j_{t-k}}\right)
$$

A direct implication of (11) is that one can compute the fraction of the variance in any given labor market stock variable accounted for by variation in any given flow transition hazard. For example, if one were interested in computing the contribution of changes in the employment-to-unemployment flow hazard, $f_{E U}$, to changes in the unemployment stock, then one could compute:

$$
\beta_{E U}^{U}=\frac{\operatorname{cov}\left(\Delta U_{t},\left[\sum_{k=0}^{t-1} \mathbf{C}_{k, t} \frac{\partial \overline{\mathbf{s}}_{t-k}}{\partial f_{E U_{t-k}}} \Delta f_{E U_{t-k}}\right]_{2,1}\right)}{\operatorname{var}\left(\Delta U_{t}\right)}
$$

Of course, the latter decomposition of variance applies to the stock of unemployed workers as a fraction of the working-age population, and therefore not directly to the unemployment rate, $u_{t} \equiv U_{t} / L_{t}$, where $L_{t} \equiv E_{t}+U_{t}$ is the labor force participation rate. However, it is straightforward to derive a decomposition of changes in $u_{t}$ using the approximate transform,

$$
\Delta u_{t} \approx\left(1-u_{t-1}\right) \frac{\Delta U_{t}}{L_{t-1}}-u_{t-1} \frac{\Delta E_{t}}{L_{t-1}}
$$

Since the labor force participation rate is the sum of $E_{t}$ and $U_{t}$, a decomposition of the labor force participation rate in terms of the contribution of changes in the flow hazards can be derived in a similar way to that of the unemployment rate.

\section{$5.2 \quad$ Results}

Table 3 summarizes the results of applying our decomposition to the estimates of the flow hazards $f_{i j}$ derived above. It reports the shares of the variance of the unemployment rate accounted for by each $f_{i j}$ based on both the unadjusted flows, as well as those adjusted for classification errors. Overall, the approach provides an accurate decomposition of unemployment variance, in the sense that the contributions of each flow sum approximately to one-the residual variance is generally less than 6 percent.

Consider first the results for the unadjusted gross flows estimates in the first row of Table 3. These confirm the well-known result that both countercyclical rates of job loss 
and procyclical rates of job finding account for a substantial fraction of the fluctuations in the aggregate unemployment rate. Over the whole sample period, around one-quarter of the cyclicality of the unemployment rate can be traced to the employment-to-unemployment hazard, and one-third to the unemployment-to-employment hazard, with a total contribution of approximately 60 percent. Thus, it is clear that an explanation of the processes of job loss and job finding is crucial to an understanding of the cyclical behavior of the labor market.

The next two columns of Table 3 , however, reaffirm the visual impression of Figure 3 that the participation margin also accounts for a substantial fraction of the rise in unemployment during recessions. The combined contribution of flows between unemployment and nonparticipation accounts for around one-third of unemployment variation. Consistent with the countercyclicality of inflows into unemployment from nonparticipation, and the procyclicality of the $U$-to- $N$ flow hazard, both flows matter. However, the $U$-to- $N$ flow hazard contributes more than the $N$-to- $U$ flow hazard.

Together, flows between unemployment and employment and flows between unemployment and nonparticipation explain the vast majority of unemployment movements; the indirect effect of flows between employment and nonparticipation is negligible.

The message of this analysis, then, is that the standard gross flows estimates of labor market transitions imply an economically-significant role for the participation margin. In what follows, we examine whether this baseline result is robust to the adjustments for classification error discussed earlier.

The remaining rows of Table 3 provide a quantitative sense of this. They implement the variance decomposition using instead adjusted estimates of flows hazards based on the Abowd and Zellner (1985) method and the deNUNified flows. The contributions of flows between unemployment and employment are adjusted upward somewhat by both corrections, accounting for approximately two-thirds of unemployment fluctuations over the whole sample period. In addition, the variance contribution of flows from $U$ to $N$ remains in the neighborhood of 20 percent in the adjusted data. Consistent with the visual impression of Figure 3, and the message of equation (4), the estimated contribution of $N$-to- $U$ flows is shaded down relative to the unadjusted gross flows data, especially for the AZ correction. Despite this, the joint contribution of the participation margin in the adjusted flows remains at around 30 percent of the variation in the unemployment rate. Thus, even after implementing adjustments for classification error, the participation margin is estimated to play a prominent role in driving cyclical unemployment dynamics.

It is instructive to compare these findings to prior literature that has focused on the 
respective roles of unemployment inflows and outflows in accounting for unemployment fluctuations in the context of a two-state framework. The results in Table 3 imply a joint variance contribution of unemployment outflows (the sum of the contributions of $U$-to- $E$ and $U$-to- $N$ flows) of approximately 60 percent for the unadjusted data, and 68 percent for the Abowd and Zellner (1985) correction. This is broadly consistent with the findings of earlier literature that has suggested something like a two-thirds outflows to one-third inflows decomposition of unemployment fluctuations (see for example Elsby, Michaels, and Solon, 2009; and Fujita and Ramey, 2009). ${ }^{13}$

\section{Stock vs. flow decompositions: a stock-flow fallacy}

The message of the above flows-based decomposition - that worker transitions between unemployment and nonparticipation contribute substantially to cyclical fluctuations in the unemployment rate - is a provocative one in the light of conventional wisdom. A prominent heuristic used to quantify the role of the participation margin in accounting for cyclical unemployment fluctuations is implicit in Figure 1. Specifically, a simple stocks-based decomposition of the variation in the unemployment rate can be derived from the following approximate relation,

$$
\Delta u_{t} \approx\left(1-u_{t-1}\right)\left(\Delta \log L_{t}-\Delta \log E_{t}\right)
$$

Thus, a close approximation to the change in the unemployment rate $\Delta u_{t}$ is the difference in the logarithmic changes in the labor force participation rate $\Delta \log L_{t}$, and the employmentto-population ratio $\Delta \log E_{t}$.

Application of this stocks-based decomposition to quarterly averages of published labor market stocks from the Bureau of Labor Statistics for the period 1967 to 2012 implies a contribution of variance in the labor force participation rate to variance in the unemployment rate of

$$
\beta_{L}^{u}=\frac{\operatorname{cov}\left(\Delta u_{t},\left(1-u_{t-1}\right) \Delta \log L_{t}\right)}{\operatorname{var}\left(\Delta u_{t}\right)} \approx-7 \text { percent. }
$$

This result stands in stark contrast to the implications of the flows-based decomposition summarized in Table 3. According to (15), the role of the participation margin is both quantitatively small, and of opposite sign, relative to that implied by the flows. The reason,

\footnotetext{
${ }^{13} \mathrm{~A}$ drawback of the earlier two-state literature is that the estimated "inflow rate" into unemployment unavoidably conflates inflows from employment and nonparticipation respectively in a non-additive way. An advantage of the three-state decomposition provided in the present paper is that it disentangles these separate effects.
} 
of course, is that the labor force participation rate is mildly procyclical in the data. It follows that a simple stocks-based decomposition will suggest that the small declines in participation that accompany recessions in fact offset slightly the rise in unemployment. Comparisons of the relative cyclicality of labor market stocks, such as this, have informed a conventional wisdom that participation decisions are not of first-order importance for an understanding of unemployment fluctuations (see, for example, Lilien and Hall, 1986, and Hall, 2008, 2009). In the remainder of this section, we explain why this conclusion is an example of a stock-flow fallacy.

The key to understanding the seeming tension between these two approaches is to note that, in a dynamic labor market, the labor force participation rate is itself shaped by the underlying behavior of worker flows, just like the unemployment rate. By contrast, stocksbased and flows-based decompositions would deliver the same conclusion if the labor market were relatively static, which is the assumption implicit in a stocks-based analysis. For example, if recessionary declines in labor force participation were brought about by the movement of a small group of individuals from unemployment to nonparticipation that subsequently were reversed during times of recovery, increases in unemployment during recessions would be mitigated by an upward spike in the $U$-to- $N$ hazard, and the two approaches would concur. Notwithstanding the fact that the $U$-to- $N$ hazard in fact falls prominently during recessions, this view of the labor market also implies low levels of worker flows. Several decades of research on worker flows supports the exact opposite view, namely that worker flows are large, and that consequently the identities of individuals in each of the labor market states are shifting continually. Under this interpretation, the observed mild procyclicality of the participation rate is instead the outcome of a subtle interaction of offsetting cyclical movements in worker flow hazards.

To illustrate this point, in the remainder of this section we present a case study that contrasts the twin recessions of the early 1980s with the Great Recession of the late 2000s. Both episodes were associated with a rise in the unemployment rate in excess of 5 percentage points. This is confirmed in Table 4, which reports the cumulative changes in the unemployment rate $\Delta u$, the $\log$ labor force participation rate $\Delta \log L$ and the $\log$ employmentto-population ratio $\Delta \log E$ respectively for the periods May 1979 to December 1982, and March 2007 to October 2009.

Viewed through the lens of the stocks-based decomposition in (15), Table 4 suggests that the contribution of the participation margin to unemployment fluctuations changed signs across the two episodes, seemingly reinforcing the rise in unemployment in the 1980s 
recessions, but moderating the rise during the Great Recession. The reason, of course, is that the labor force participation rate was rising as a trend phenomenon in the earlier episode, and now appears to be on a trend decline, as shown in Figure 1.

Should one conclude from this that the role of the participation margin in accounting for cyclical unemployment has shifted fundamentally as a result of these differing secular trends? The message from the worker flows is a resounding "no." Figure 4 presents the estimated contribution of each labor market flow to the changes in the unemployment rate during these two episodes. The role of flows between unemployment and nonparticipation is both quantitatively significant, and of similar magnitude, across the two recessionary periods, accounting for approximately one-third of the rise in the unemployment rate in each case.

To reconcile the divergent behavior of the participation rate across the two recessionary periods, we exploit a virtue of the flows-based decomposition in equation (11), namely that it can be applied to any combination of labor market stocks, including the labor force participation rate, $L \equiv E+U$. The final panels of Figure 4 present the analogous contributions of worker flows to the evolution of labor force participation. In both downturns, flows between unemployment and nonparticipation placed upward pressure on participation, consistent with the cyclical behavior of these flows discussed earlier. However, this tendency is almost exactly offset by the effect of flows between unemployment and employment. The intuition for the latter is somewhat subtle: Although the primary effect of flows between unemployment and employment in times of recession is to reduce employment and raise unemployment, unemployed workers are much more likely to leave the labor force compared to employed workers, that is $f_{U N} \gg f_{E N} \cdot{ }^{14}$

The key to the different trajectories in participation between the 1980s recessions and the Great Recession, then, is the comparative effects of flows between employment and nonparticipation. In particular, these flows imparted a substantial negative effect on participation during the most recent downturn, while their effect was more muted in the early 1980s. This difference, which can be attributed to changing secular trends in the employment-tononparticipation flow rate in Figure 3, is what drives the opposite paths of the labor force participation rate across the two episodes. Since flows between employment and nonparticipation are largely neutral with respect to the unemployment rate, it would be fallacious to infer the contributon of the participation margin to recessionary increases in unemployment

\footnotetext{
${ }^{14}$ Another way to see this is to consider the implied steady-state labor force participation rate, $L^{*}=$ $1-N^{*}=1-\frac{f_{E N} E^{*}+f_{U N} U^{*}}{f_{N E}+f_{N U}}$. As employment falls and unemployment rises, more weight is placed on the labor force exit rate from unemployment $f_{U N}$, which is much larger than its counterpart from employment $f_{E N}$.
} 
from the behavior of the stock of labor force participants, which is itself shaped by (different) worker flows.

\section{Toward understanding the participation margin}

The preceding sections have highlighted that the flow transition rates between unemployment and nonparticipation are prominently cyclical; that adjustments for classification errors and time aggregation do not eliminate this cyclicality; and that this variation contributes substantially to cyclical unemployment fluctuations. An important question, then, is what might explain the observed cyclicality of these flows. In this section, we assess a number of hypotheses for why the participation margin appears to be so important. ${ }^{15}$ Our approach is to explore these hypotheses by delving into the pattern of heterogeneity in worker flows at the participation margin that can be observed in available data.

\subsection{History dependence and labor force exit}

The first channel that we explore revives an insight of Akerlof and Main (1981) that, in practice, the structure of worker flow transitions may depart considerably from the descriptive first-order Markov structure in equation (5) that has informed the majority of research on labor market flows. ${ }^{16}$ In particular, worker flows may exhibit history dependence, whereby individual workers' transition rates are related to their past labor market status, and may also vary across workers. Consequently, cyclical changes in the composition of the unemployed across these different dimensions of heterogeneity can influence the evolution of average worker flows over the cycle.

The specific hypothesis we explore is whether the behavior of the average unemploymentto-nonparticipation rate depicted in Figure 3 can be traced to cyclical shifts in labor force attachment of the nonemployed. In particular, a stylized feature of recessions in the United States is the burst of job loss that occurs at the onset of a downturn. If such workers are more than averagely attached to the labor market, it is plausible that they will continue

\footnotetext{
${ }^{15} \mathrm{~A}$ natural candidate explanation might be the role of extensions in the duration of unemployment insurance (UI) that accompany recessions, with the Great Recession of 2008 to 2010 being a prominent example. However, estimates of the impact of such UI extensions suggest a modest impact on unemployment (see Aaronson, Mazumder, and Schecter, 2010; Farber and Valletta, 2011; Fujita, 2010; Nakajima, 2010; Rothstein, 2011; Valletta and Kuang, 2010; and Valletta, 2010).

${ }^{16}$ A recent exception is Gomes (2012), who highlights the existence of history dependence in worker flows in the United Kingdom.
} 
searching for employment rather than transitioning out of the labor force. An important potential signal of labor market attachment would be history-dependence in worker flows: Individuals who have been attached to the labor market in the past would exhibit a lower propensity to exit the labor force, and cyclical changes in the distribution of labor market attachment will in turn drive cyclical changes in average worker flows at the participation margin. ${ }^{17}$

To study the magnitude of this channel in accounting for the cyclicality of transitions between unemployment and out of the labor force, we use Current Population Survey microdata for which individual records have been matched across all eight months in sample. Using these data, we compute the transition rates between $U$ and $N$ conditional on a full interaction of gender, age, education, past labor force status (defined as status one year prior to the survey), and reason for unemployment (job leavers, job losers and labor force entrants). ${ }^{18}$

Table 5 reports the relevant flow transition probabilities for different groups of workers, averaged over the period 1979 to $2010 .{ }^{19}$ The table reveals that female workers, both younger and older workers, less educated workers, entrants, and workers who were not employed in the past all are more likely to flow from unemployment to nonparticipation. Quite sensibly, and consistent with the premise underlying the above hypothesis, the common thread that unites these observations is that flows between unemployment and nonparticipation are more common among workers who tend to be less attached to the labor force.

Importantly, we also find that the composition of the unemployment pool becomes skewed towards workers that are more attached to the labor force during recessions. Specifically, during recessions we observe increases in the unemployment shares of prime-aged men, as well as workers who were employed in the past. Since unemployed members of these groups are less likely to exit the labor force, these compositional shifts potentially could account for the observed decline in the average $U$-to- $N$ flow rate during recessions. This observation dovetails with the findings of Mueller (2012), who documents that the composition of unemployed

\footnotetext{
${ }^{17} \mathrm{We}$ also examined the role of such compositional forces on other labor market flows, but found only modest effects on flows originating from employment and nonparticipation. The simple reason is that both the employment and nonparticipant stocks are much larger than the unemployment stock. Consequently, the composition of these larger stocks is influenced less by cyclical fluctuations.

${ }^{18}$ Further disaggregation of job losers into temporary layoffs and permanent job losers, and of labor force entrants into new entrants and re-entrants were not pursued because the 1994 CPS redesign led to important changes in the measurement of these subcategories.

${ }^{19}$ Note that these transition probabilities differ slightly from those reported in Figure 3. In particular, they are based on the raw transition probabilities computed from CPS microdata matched across all eight months in sample, and are not adjusted for margin error or temporal aggregation.
} 
workers shifts towards individuals with higher past wages. ${ }^{20}$

To quantify the magnitude of this effect, we compute "counterfactual" $U$-to- $N$ transition probabilities for each of the last five recessionary episodes, holding constant the unemployment shares by gender, age, education, prior status, and reason for unemployment at their beginning-of-recession values. Table 6 reports the actual and counterfactual percentage declines in the $U$-to- $N$ transition probability over the course of each recessionary trough-to-peak ramp up in the unemployment rate since 1979.

The message of Table 6 is that a large part of the cyclicality of $U$-to- $N$ flows can be attributed to cyclical shifts in the composition of unemployed workers. In particular, depending on the recession, around 75 percent of the recessionary decline in the rate at which unemployed workers exit the labor force can be traced to compositional shifts.

This result is striking from a number of perspectives. First, it is important to remember that the compositional adjustment in Table 6 is based on just a few observable factors, specifically prior labor force status, reason for unemployment, age, education and gender. Since this small set of variables are imperfect proxies for labor force attachment, it is possible that additional unobservable dimensions of attachment would imply an even larger composition effect.

A second notable feature of the results of Table 6 is that they contrast interestingly with the analyses of Baker (1992) and Shimer (2012). Both of the latter two analyses examined the hypothesis that compositional shifts in the unemployment pool could account for cyclical changes in the rate of outflow from unemployment - the "heterogeneity hypothesis" of Darby, Haltiwanger and Plant (1986). Seemingly in contrast to the results in Table 6, however, Baker and Shimer find little role for compositional effects on the cyclical behavior of the outflow rate from unemployment.

Our own analysis highlights two factors that explain the difference between the results of Table 6 and those of Baker and Shimer. The main factor is that these prior analyses did not adjust for compositional shifts in prior labor market status, which we find play an important role in the composition adjustment in Table 6. In addition, though, it is important to recall that the outflow rate analyzed by Baker and Shimer is in fact the sum of the unemployment-to-nonparticipation rate that we analyze, and the unemployment-toemployment rate. Interestingly, there are some small offsetting composition effects in the

\footnotetext{
${ }^{20}$ Unfortunately, survey questions pertaining to wages are asked of only one-quarter of the CPS sample (specifically, those in the fourth and eighth months in sample, the "outgoing rotation groups"). Consequently, we found that adding past wages to the history resulted in sample sizes that were too thin to estimate composition-adjusted flows with sufficient accuracy.
} 
latter that serve to mute the overall effect of composition on total unemployment outflows. This makes sense: The cyclical shift toward higher labor market attachment that we have highlighted will tend to elevate the $U$-to- $E$ transition rate as well as depress the $U$-to- $N$ rate that we have focused on in this subsection.

\subsection{Labor force entry}

Although the majority of the contribution of the participation margin to unemployment fluctuations is accounted for by cyclical changes in the rate of labor force exit from unemployment, Table 3 also highlights that countercyclicality in labor force entry into unemployment also contributes. In this subsection, we assess available evidence for the role of various channels that may account for this observation.

To this end, it is worth noting that our analysis thus far already provides a perspective on some of these hypotheses. First, a novel result of section 3 was to show how it is possible for the presence of classification errors to induce a countercyclical bias in measured transitions between unemployment and nonparticipation. The logic is that, since the majority of misclassification is between these two states, the population at risk of being misclassified rises during recessions, so that measured worker flows between $U$ and $N$ tend to be overstated in downturns. Table 3 suggests that adjustments for classification error do reduce the contribution of labor force entry into unemployment. However, they do not eliminate the cyclicality of $N$-to- $U$ flows, and the magnitude of the effect depends on the adjustment for spurious transitions. Thus, classification errors provide a partial account for the countercyclicality of labor force entry into unemployment.

A second potential explanation for the countercyclicality of $p_{N U}$ relates to time aggregation. An implication of the large magnitude of the job-finding rate in Figures 2 and 3 is that many job seekers are able to find jobs within the month between surveys. It thus seems plausible that reductions in rates of job finding during recessions may imply that labor force entrants are less likely to find a job during the month between surveys, leading to increases in realized $N$-to- $U$ transitions. This mechanism, however, is implicit in the time aggregation adjustment that we implement. Inspection of Figures 2 and 3 reveals that these adjustments for time aggregation do little to dampen the cyclicality of the $N$-to- $U$ rate. ${ }^{21}$ Thus, time

\footnotetext{
${ }^{21}$ It is important to note that conventional time aggregation corrections - such as the one applied in this paper, and in the majority of recent literature on worker flows - invoke an assumption that the underlying flow hazards are constant across duration. If new labor force entrants were to face higher job-finding propensities than those who have been searching for some time, then it is possible that time aggregation has more prominent cyclical effects. See Krusell, Mukoyama, Rogerson and Şahin (2012) for an example of such a
} 
aggregation does not appear to contribute to the role of labor force entry.

The final channel we consider is the added worker effect. This is the idea that nonparticipant individuals within a household - typically the female partner-may begin to look for work during recessions to replace lost income arising from the job loss of another household member - typically the male partner. Since recessions are periods of relatively weak job-finding prospects, many such women will be expected to transition into unemployment and as realized $N$-to- $U$ flows.

An extensive analysis of the added worker effect is beyond the scope of our paper. ${ }^{22}$ However, a sense of its likely importance can be gained if we again use our data to delve into the heterogeneity of flows into unemployment due to labor force entry. Figure 5 plots the basic time series of $p_{N U}$, disaggregated by gender and age. A number of features of Figure 5 challenge the added worker effect channel. First, in terms of the levels of the flow rates, men are more likely than women to enter unemployment from out of the labor force. Most starkly, $N$-to- $U$ rates among prime-aged men are double those among prime-aged women. Second, it is clear that the cyclicality of these flows is not a phenomenon driven by prime-aged women, the group most likely to account for the added worker effect. Rather, again we see that the cyclicality of $p_{N U}$ appears to be larger among men than women, with prime-aged men being conspicuously cyclical. Thus, a simple added worker effect story does not provide a strong account of the countercyclicality in labor force entry.

The cyclical behavior of rate of labor force entry into unemployment therefore remains a topic for further research.

\section{Summary and discussion}

An often-neglected empirical regularity in standard estimates of worker flows in the United States is that flows between unemployment and out of the labor force display prominent fluctuations over the business cycle. Moreover, these fluctuations at the participation margin contribute towards increasing unemployment in times of recession: Inflows into unemployment from nonparticipation rise in downturns; the rate at which jobseekers exit the labor

mechanism.

${ }^{22}$ A recent paper by Juhn and Potter (2007) has analyzed the importance of the added worker effect. They find that labor market transitions of husbands and wives were negatively related in the 1960 s and 1970 s. In contrast, in the 1990s and 2000s labor market transitions of spouses were positively related. They suggest that the added worker effect was important in the 1960s and 1970s when female labor force participation was lower, but that this effect largely disappeared in the 1990s and early 2000s as a consequence of rising female participation and positive assortative matching. 
force falls in times of recession.

In this paper, we have quantified the magnitude of this channel in accounting for cyclical unemployment, and considered its robustness to an array of adjustments for time aggregation in measured flows and classification errors in recorded labor market status. We have found that the contribution of the participation margin is quantitatively substantial, accounting for around one-third of cyclical unemployment movements. Moreover, this conclusion continues to hold after adjustments of the data to correct for spurious transitions. Finally, we have shown that, viewed through this lens, conventional wisdom on the participation margin informed by the cyclical behavior of labor market stocks is based on a stock-flow fallacy that implicitly neglects the role of worker flows in shaping the stock of labor force participants.

An important topic for further research, then, is to identify explanations for this phenomenon. We have highlighted one particular fruitful line of research. We have shown that a large part of the cyclical variation in worker flows at the participation margin can be traced to shifts in the composition of labor market attachment among the nonemployed in times of recession. The wave of job losses that accompanies the start of recessions skews the unemployment pool towards a group of workers who are more than averagely attached to the labor market, and can be expected to continue searching for employment rather than transitioning out of the labor force. We show that individuals who have been attached to the labor market in the past exhibit a lower propensity to exit the labor force, and that there are notable cyclical changes in the distribution of labor market attachment over the business cycle. This mechanism is quantitatively important and the majority of the cyclicality of unemployment-to-nonparticipation flows can be traced to the shift in the composition of unemployed workers towards more attached workers during the recessions.

In contrast, accounting for the countercyclicality of labor force entry into unemployment remains a challenge. While our analysis has shown that classification errors may partially explain this phenomenon, it also casts doubt on other commonly-cited channels, such as temporal aggregation and the added worker effect. Of particular note is that cyclical fluctuations in labor force entry are broad-based across both young and prime-aged, male and female workers. Further explanations to account for this phenomenon are needed.

In the light of these results, it is tempting to conclude that future research should focus less on the cyclical variation in unemployment, and perhaps direct attention instead toward fluctuations in employment and nonemployment - that is, the sum of unemployment and nonparticipation. We argue that our results suggest a more nuanced set of conclusions.

First, the observation that marginally-attached workers are an important determinant of 
measured unemployment fluctuations at the participation margin tells us something about the underlying economics of labor market fluctuations. It suggests that worker heterogeneity is a crucial ingredient to an understanding of unemployment cyclicality. And, just as one would expect from simple economics, it is those workers on the margin that shape market outcomes.

Second, it is important to recognize that the presence of marginally-attached workers in the unemployment pool does not imply that cyclical fluctuations in unemployment are less meaningful. A key lesson of our analysis is that the labor market attachment of the unemployed is not constant over time - it rises in times of recession. Far from underscoring the unimportance of unemployment fluctuations, the latter instead emphasizes the particular importance of unemployment in times of recession. And, it is again worth noting that this is precisely what simple economics would predict in a world with worker heterogeneity - that reductions in employment during recessions displace individuals into the jobless pool that are relatively attached to the labor market.

These observations echo the early work of Clark and Summers (1979), who were among the first to emphasize the fundamentally ambiguous distinction between unemployment and nonparticipation. Nonetheless, they highlight the substantial heterogeneity in the experience of unemployment among the jobless, noting the importance of long spells in accounting for total unemployment. Our findings complement this view by stressing the roles of labor force attachment in generating long spells of unemployment, and of cyclical changes in the composition of attachment in shaping the cyclicality of unemployment.

Our conclusions also dovetail interestingly with recent theoretical research that has sought to provide a joint understanding of unemployment and labor force participation. A feature of much of this research is that it often has focused on devising models that can account for the cyclical comovement of labor market stocks. ${ }^{23}$ While such research is a distinguished outlier relative to the abundance of theoretical and empirical research that has ignored the participation margin, our analysis emphasizes that the latter is a necessary, but not sufficient condition for a further desideratum, namely that our models provide an account of the cyclical behavior of underlying worker flows.

Toward that end, the recent work of Krusell, Mukoyama, Rogerson and Şahin (2012) has provided a theoretical framework that distils much of the economics suggested by our empirical analysis of worker flows. They demonstrate how a hybrid model of unemployment

\footnotetext{
${ }^{23}$ See, for example, Tripier (2004); Veracierto (2008); Christiano et al. (2010); Galí et al. (2011); Ebell (2011); Haefke and Reiter (2011); and Shimer (2011).
} 
and labor supply is able to replicate both the levels and cyclical fluctuations in worker flows at the participation margin. Consistent with our empirical findings, worker heterogeneity, and the implied cyclical changes in the composition of the unemployment pool, play a crucial role in their model's ability to match worker flows at the participation margin.

\section{$9 \quad$ References}

Aaronson, Daniel, Bhashkar Mazumder, and Shani Schechter. 2010. "What is behind the rise in long-term unemployment?" Federal Reserve Bank of Chicago Economic Perspectives 2Q/2010: 28-51.

Abowd, John M. and Arnold Zellner. 1985. "Estimating Gross Labor-Force Flows." Journal of Business and Economic Statistics 3(3): 254-283.

Abraham, Katharine G., and Robert Shimer, 2002. "Changes in Unemployment Duration and Labor Force Attachment" in A.B. Krueger and R.M. Solow, eds., The Roaring Nineties, New York: The Russell Sage Foundation: 367-420.

Akerlof, George A. and Brian G. M. Main. 1981. "Pitfalls in Markov Modeling of Labor Market Stocks and Flows." Journal of Human Resources, 16(1): 141-151.

Alvarez, Fernando and Marcelo Veracierto. 1999. "Labor-Market Policies in an Equilibrium Search Model." NBER Macro Annual 1999, edited by Ben Bernanke and Julio Rotemberg: 265-304.

Andolfatto, David and Paul Gomme. 1996. "Unemployment Insurance and Labor Market Activity in Canada." Carnegie Rochester Series on Public Policy 44 (1996): 47-82.

Andolfatto, David, Paul Gomme, and Paul Storer. 1998. "US Labour Market Policy and the Canada-US Unemployment Rate Gap." Canadian Public Policy-Analyse de Politiques 24: $210-232$.

Barnichon, Regis, and Andrew Figura. 2012. "Labor Market Heterogeneities, Matching Efficiency and the Cyclical Behavior of the Job Finding Rate." Finance and Economics Discussion Series 2010-48.

Barnichon, Regis and Chistopher J. Nekarda. 2012. "Using Labor Force Flows to Forecast the Labor Market." Unpublished, CREi.

Blanchard, Olivier J. and Peter Diamond. 1990. "The Cyclical Behavior of the Gross Flows of U.S. Workers." Brookings Papers on Economic Activity, 1990(2): 85-155. 
Braun, Helge, Reinout de Bock, and Ricardo DiCecio. 2006. "Aggregate Shocks and Labor Market Fluctuations." Federal Reserve Bank of St. Louis working paper 2006-004.

Chua, Tin Chiu and Wayne A. Fuller. 1987. "A Model for Multinomial Response Error Applied to Labor Flows." Journal of the American Statistical Association, 82(397): 46-51.

Christiano, Lawrence J., Mathias Trabandt and Karl Walentin. 2010. "Involuntary Unemployment and the Business Cycle." Working Paper No. 15801, National Bureau of Economic Research.

Clark, Kim B. and Lawrence H. Summers. 1979. "Labor Market Dynamics and Unemployment: A Reconsideration." Brookings Papers on Economic Activity, 1979(1): 13-60.

Darby, Michael R., John C. Haltiwanger, and Mark W. Plant. 1986. "The Ins and Outs of Unemployment: The Ins Win." Working Paper No. 1997, National Bureau of Economic Research.

Ebell, Monique. 2011. "On the Cyclicality of Unemployment: Resurrecting the Participation Margin." Labour Economics, 18(6): 822-836.

Elsby, Michael W. L., Bart Hobijn, and Ayşegül Şahin. Forthcoming. "Unemployment Dynamics in the OECD." Review of Economics and Statistics.

Elsby, Michael W. L., Ryan Michaels, and Gary Solon. 2009. "The Ins and Outs of Cyclical Unemployment." American Economic Journal: Macroeconomics, 1(1): 84-110.

Elsby, Michael W. L., Jennifer C. Smith and Jonathan Wadsworth. 2011. "The Role of Worker Flows in the Dynamics and Distribution of U.K. Unemployment." Oxford Review of Economic Policy, 27(2): 338-363.

Farber, Henry S., and Robert G. Valletta. 2011. "Extended Unemployment Insurance and Unemployment Duration in The Great Recession: The U.S. Experience." Mimeo, Federal Reserve Bank of San Francisco and Princeton University, June.

Feng, Shuaizhang, and Yingyao Hu. 2012. "Misclassification Errors and the Underestimation of U.S. Unemployment Rates." American Economic Review, forthcoming.

Frazis, Harley J., Edwin L. Robison, Thomas D. Evans, and Martha A. Duff. 2005. "Estimating Gross Flows Consistent with Stocks in the CPS" Monthly Labor Review, September 2005: 3-9.

Fujita, Shigeru. 2010. "Effects of the UI Benefit Extensions: Evidence from the Monthly CPS." Working Paper No. 10-35, Federal Reserve Bank of Philadelphia, November.

Fujita, Shigeru and Garey Ramey. 2006. "The Cyclicality of Job Loss and Hiring." Working paper, University of California, San Diego. 
Fujita, Shigeru and Garey Ramey. 2009. "The Cyclicality of Separation and Job Finding Rates." International Economic Review, 50: 415-430.

Gali, Jordi, Frank Smets and Fafael Wouters. 2011. "Unemployment in an Estimated New Keynesian Model." Unpublished, CREi.

Garibaldi, Pietro and Etienne Wasmer. 2005. "Equilibrium Search Unemployment, Endogenous Participation, and Labor Market Flows." Journal of European Economic Association 3 (2005): 851-882.

Haefke, Christian and Michael Reiter. 2011. "What Do Participation Fluctuations Tell Us About Labor Supply Elasticities?" Discussion Paper No. 6039, IZA.

Hall, Robert E. 2005a. "Job Loss, Job-Finding, and Unemployment in the U.S. Economy over the Past Fifty Years." NBER Macroeconomics Annual, 101-137.

Hall, Robert E. 2005b. "Employment Efficiency and Sticky Wages: Evidence from Flows in the Labor Market." Review of Economics and Statistics, 87(3): 397-407.

Hall, Robert E. 2008. "Cyclical Movements along the Labor Supply Function." In Katharine Bradbury, Christopher Foote, and Robert Triest (eds.) Labor Supply in the New Century, Federal Reserve Bank of Boston, 241-264.

Hall, Robert E. 2009. "Reconciling Cyclical Movements in the Marginal Value of Time and the Marginal Product of Labor." Journal of Political Economics, 117(2): 281-323.

Juhn, Chinhui and Simon Potter. 2007. "Is There Still an Added Worker Effect?" Federal Reserve Bank of New York Staff Report No. 310.

Kaitz, Hyman. 1970. "Analyzing the Length of Spells of Unemployment." Monthly Labor Review, 93(11): 11-20.

Kim, S. 2001. Labor Force Participation, Worker Flows and Labor Market Policies. Ph.D. Dissertation, University of Pennsylvania.

King, Thomas B. 2011. "Variable Participation and Cyclical Unemployment." Federal Reserve Board, mimeo.

Krusell, Per, Toshihiko Mukoyama, Richard Rogerson and Ayşegül Şahin. 2010a. "Aggregate Labor Market Outcomes: The Role of Choice and Chance." Quantitative Economics, 1(1): $97-127$.

Krusell, Per, Toshihiko Mukoyama, Richard Rogerson and Ayşegül Şahin. 2010b. "A ThreeState Model of Worker Flows in General Equilibrium." Journal of Economic Theory, 146(3): 812-844. 
Krusell, Per, Toshihiko Mukoyama, Richard Rogerson and Ayşegül Şahin. 2012. "Gross Worker Flows over the Business Cycle." Working Paper No. 17779, National Bureau of Economic Research.

Kudlyak, Marianna, and Felipe Schwartzman. 2012. "Accounting for Unemployment in the Great Recession: Nonparticipation Matters." Federal Reserve Bank of Richmond Working Paper Series 12-04.

Lilien, David M., and Robert E. Hall. 1986. "Cyclical Fluctuations in the Labor Market." In O. Ashenfelter and R. Layard (Eds.), Handbook of Labor Economics, Volume 2, Elsevier.

Marston, Stephen T. 1976. "Employment Instability and High Unemployment Rates." Brookings Papers on Economic Activity, 1976(1): 169-210.

Mortensen, Dale T., and Christopher A. Pissarides. 1994. "Job Creation and Job Destruction in the Theory of Unemployment." Review of Economic Studies, 61(3): 397-415.

Mueller, Andreas I. 2012. "Separations, Sorting and Cyclical Unemployment." Discussion Paper No. 6849, IZA.

Nakajima, Makoto. 2011. "A Quantitative Analysis of Unemployment Benefit Extensions." Federal Reserve Bank of Philadelphia, mimeo.

National Commission on Employment and Unemployment Statistics. 1979. Counting the Labor Force. Washington, DC: U.S. Government Printing Office.

Perry, George L. 1972. "Unemployment Flows in the U.S. Labor Market." Brookings Papers on Economic Activity, 1972(2): 245-78.

Poterba, James M. and Lawrence H. Summers. 1986. "Reporting Errors and Labor Market Dynamics." Econometrica, 54(6): 1319-1338.

Pries, Michael and Richard Rogerson. 2009. "Search Frictions and Labor Market Participation." European Economic Review 53 (2009): 568-587.

Rothstein, Jesse. 2011. "Unemployment Insurance and Job Search in the Great Recession." Brookings Papers on Economic Activity, Fall 2011.

Shimer, Robert. 2011. "Job Search, Labor Force Participation, and Wage Rigidities." Unpublished, University of Chicago.

Shimer, Robert. 2012. "Reassessing the Ins and Outs of Unemployment." Review of Economic Dynamics, 15(2): 127-148.

Smith, Jennifer C. 2011. "The Ins and Outs of UK Unemployment." Economic Journal, 121(552): 402-444. 
Tripier, Fabien. 2004. "Can the Labor Market Search Model Explain the Fluctuations of Allocations of Time?" Economic Modelling, 21(1): 131-146.

Valletta, Robert G. 2010. "House Lock and Structural Unemployment." Federal Reserve Bank of San Francisco, mimeo.

Valletta, Robert G., and Katherine Kuang. 2010. "Extended Unemployment and UI Benefits." FRB SF Economic Letter 2010-12.

Veracierto, Marcelo. 2008. "On the Cyclical Behavior of Employment, Unemployment, and Labor Force Participation." Journal of Monetary Economics 55 (2008): 1143-1157. 
Table 1: Abowd and Zellner (1985) estimates of classification errors

\begin{tabular}{lccc}
\hline \hline Original & \multicolumn{3}{c}{ Status determined on reinterview } \\
interview status & Employed & Unemployed & Non-participant \\
\hline Employed & 98.78 & 1.91 & 0.50 \\
Unemployed & 0.18 & 88.57 & 0.29 \\
Non-participant & 1.03 & 9.52 & 99.21 \\
\hline \hline
\end{tabular}

Source: Abowd and Zellner (1985, Table 6).

Table 2: Recoding of unemployment-nonparticipation cyclers

\begin{tabular}{ccc}
\hline \hline & Measured & Recoded \\
\hline \multirow{4}{*}{ NUNs } & NNUN & NNNN \\
& NUNN & NNNN \\
& ENUN & ENNN \\
& NUNE & NNNE \\
& .NUN & .NNN \\
& NUN. & NNN. \\
\hline \multirow{6}{*}{ UNUs } & UUNU & UUUU \\
& UNUU & UUUU \\
& EUNU & EUUU \\
& UNUE & UUUE \\
&.$U N U$ &.$U U U$ \\
& UNU. & UUU. \\
\hline \multirow{2}{*}{ Unadjusted } & NUNU & NUNU \\
& UNUN & UNUN \\
\hline \hline
\end{tabular}

Note: The notation ABCD refers to a sequence of transitions associated with up to four consecutive monthly individual labor market states (that is, from A to B to C to D). A "." is used to denote missing observations. 


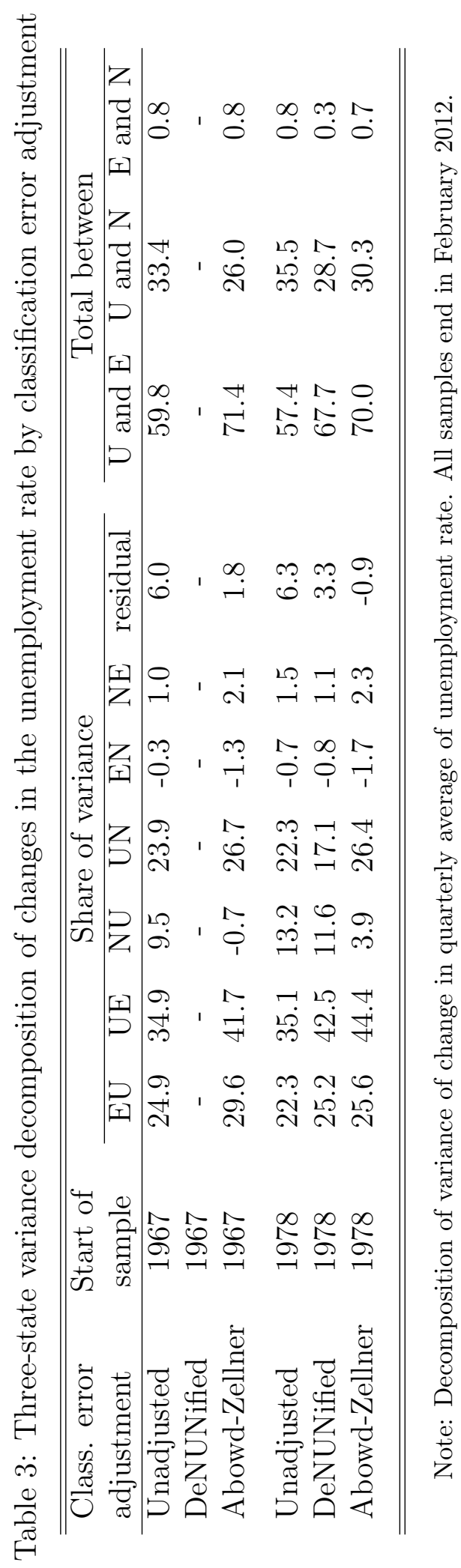


Table 4: Stocks-based decomposition of the rise in the unemployment rate in the twin recessions of the 1980s and the most recent downturn

\begin{tabular}{lccc}
\hline \hline Recessionary period & $\Delta u$ & $\Delta \log (L)$ & $\Delta \log (E)$ \\
\hline May 1979 to Dec 1982 & 0.052 & 0.013 & -0.045 \\
Mar 2007 to Oct 2009 & 0.056 & -0.018 & -0.079 \\
\hline \hline
\end{tabular}

Table 5: Heterogeneity in unemployment-to-nonparticipation flow probabilities

\begin{tabular}{lc}
\hline \hline Gender & $p_{U N}$ (percent) \\
\hline Men & 17.8 \\
Women & 26.6 \\
\hline \hline Age & 28.6 \\
\hline 16 to 24 & 17.5 \\
25 to 54 & 23.9 \\
55 and over & \\
\hline \hline Education & 28.5 \\
\hline Less than high school & 19.1 \\
High school & 20.1 \\
Some college & 15.4 \\
College & \\
\hline \hline Labor force status a year ago & 14.7 \\
\hline$E$ & 19.4 \\
$U$ & 36.6 \\
\hline & \\
\hline Reason for unemployment & 19.7 \\
\hline Job leaver & 13.3 \\
Job loser & 34.3 \\
Entrant
\end{tabular}

Note: Transition probabilities are calculated using Current Population Survey microdata matched across all eight months in sample. 
Table 6: Actual and counterfactual declines in unemployment-to-nonparticipation transition probabilities by recession

\begin{tabular}{lcc}
\hline \hline & \multicolumn{2}{c}{ Percent change in $p_{U N}$} \\
\hline Recessionary period & Actual & Counterfactual \\
\hline 1979Q2 to 1980Q3 & -14.9 & -1.6 \\
1981Q2 to 1982Q4 & -20.0 & -6.5 \\
1989Q1 to 1992Q2 & -10.9 & -2.0 \\
2000Q4 to 2003Q2 & -16.3 & -7.3 \\
2006Q4 to 2009Q4 & -20.2 & -6.0 \\
\hline \hline
\end{tabular}

Note: Reported are percentage changes in the transition probabilities from quarterly trough to peak in the unemployment rate around each recession. Counterfactual declines are based on composition adjustment for age, gender, education, labor force status one year prior, and reason for unemployment using Current Population Survey microdata. 
Figure 1: Unemployment and labor force participation rates: unadjusted and adjusted for spurious transitions
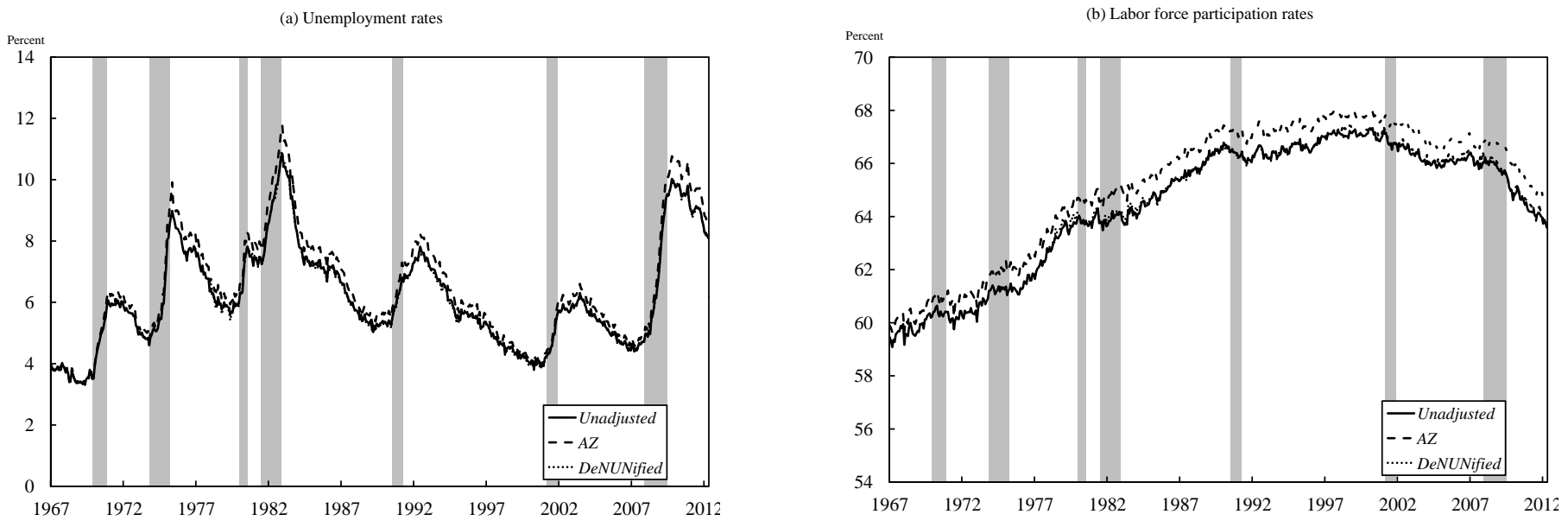
Figure 2: Monthly flow transition probabilities corrected for margin error: unadjusted and adjusted for spurious transitions
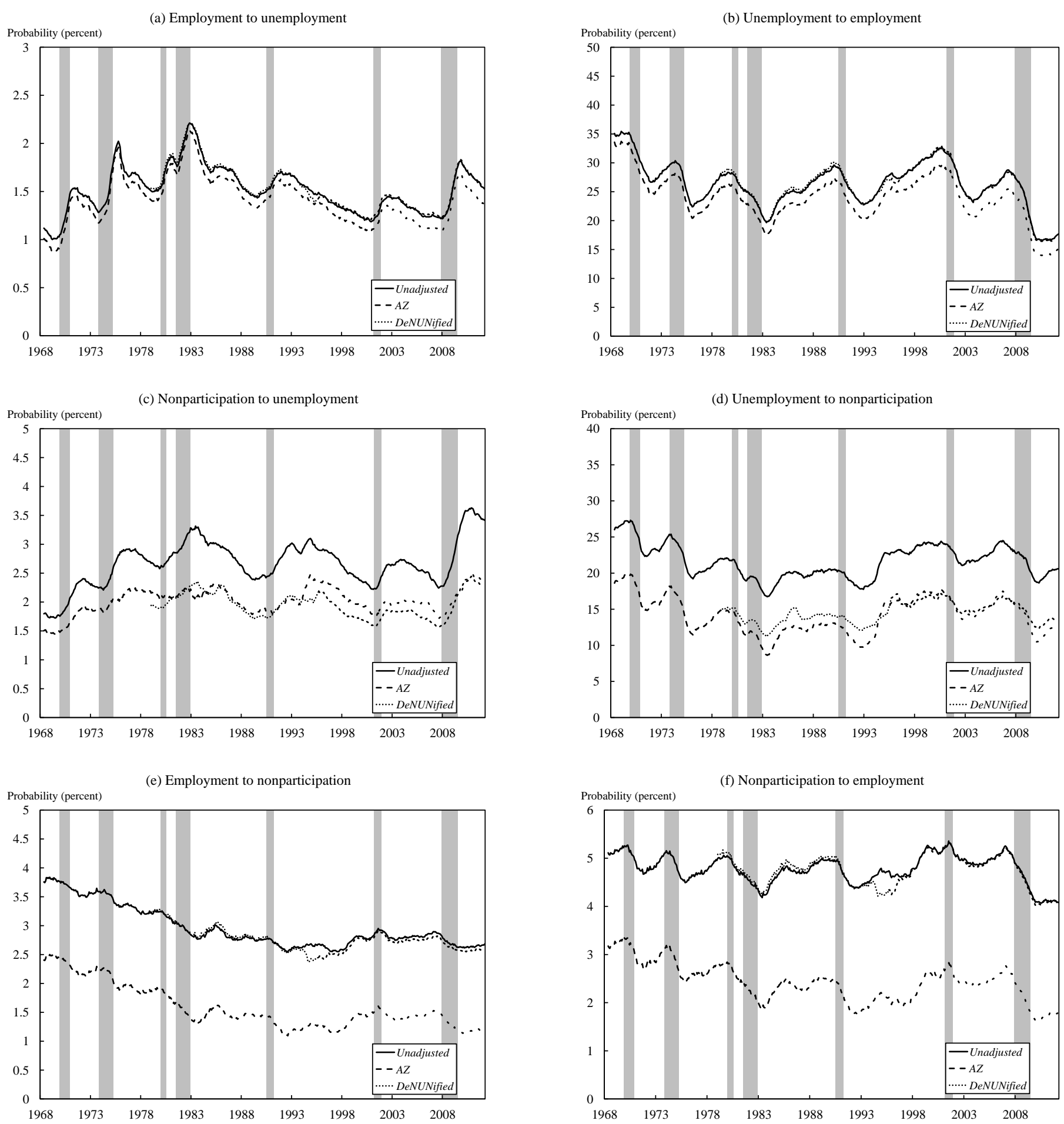
Figure 3: Implied monthly flow transition probabilities corrected for margin error and time aggregation: unadjusted and adjusted for spurious transitions

(a) Employment to unemployment

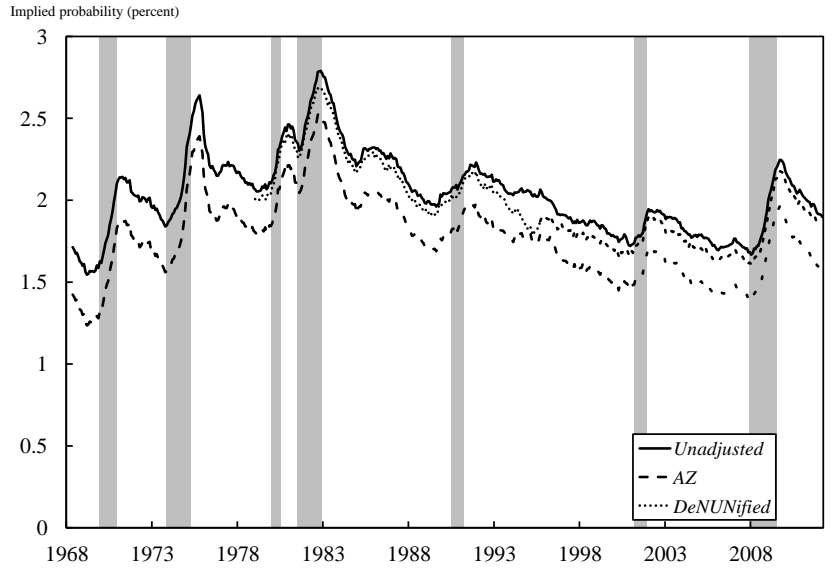

(c) Nonparticipation to unemployment

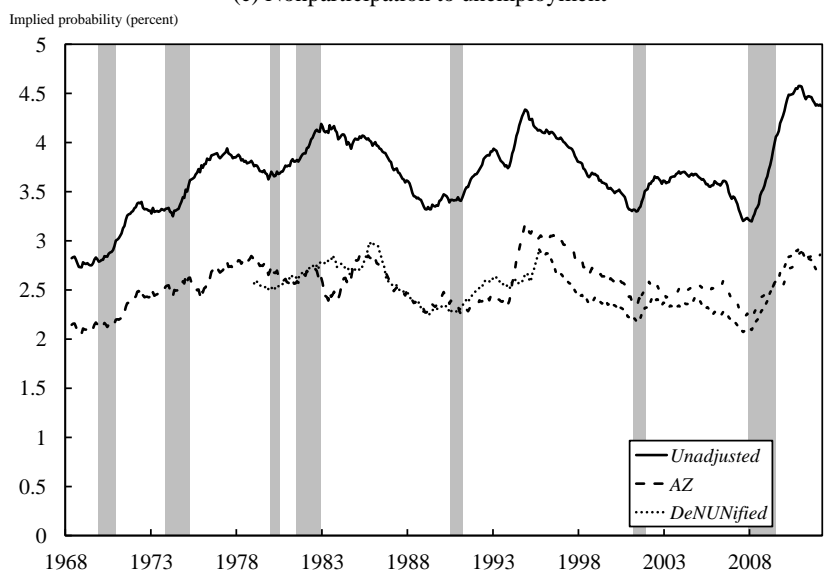

(e) Employment to nonparticipation

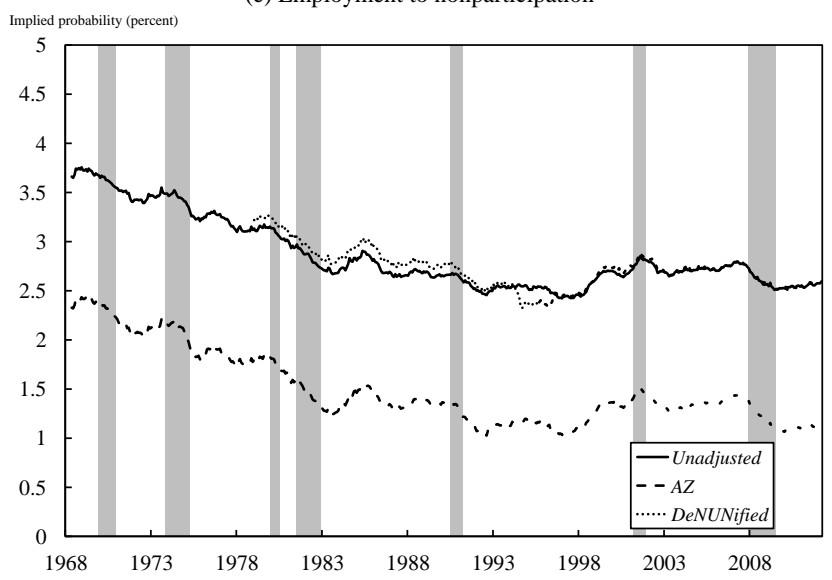

(b) Unemployment to employment

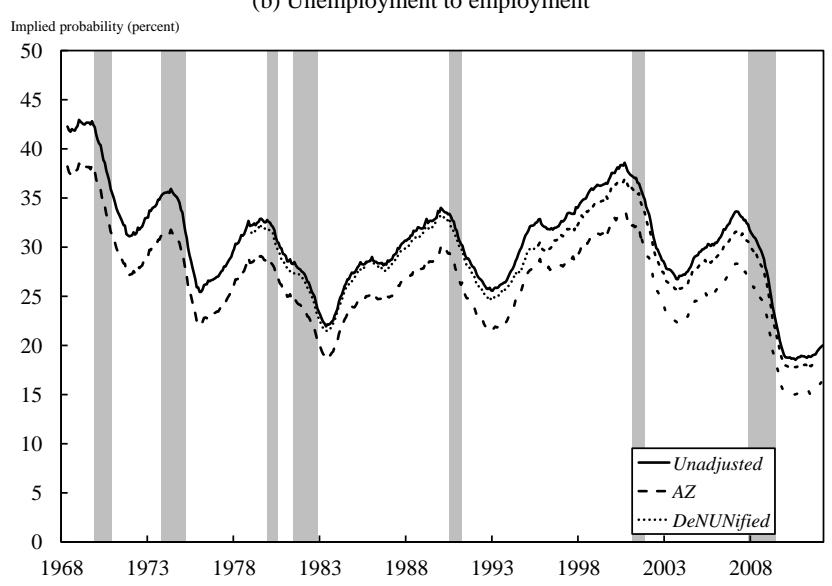

(d) Unemployment to nonparticipation

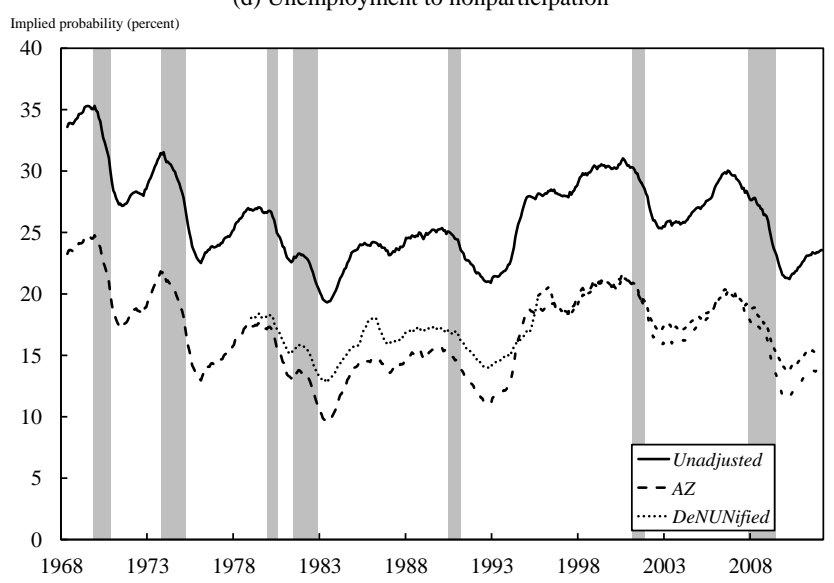

(f) Nonparticipation to employment

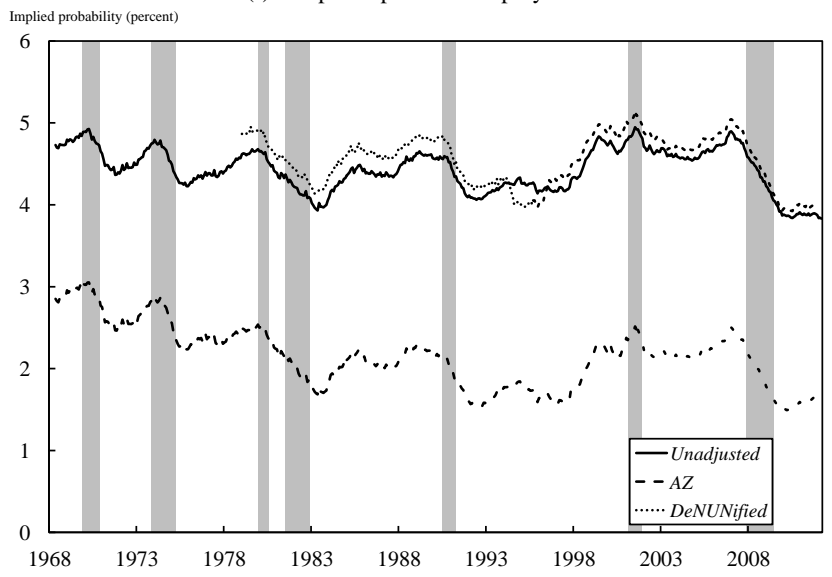


Figure 4: Contributions of labor market flows to changes in stocks during the twin recessions of the 1980s and the most recent downturn
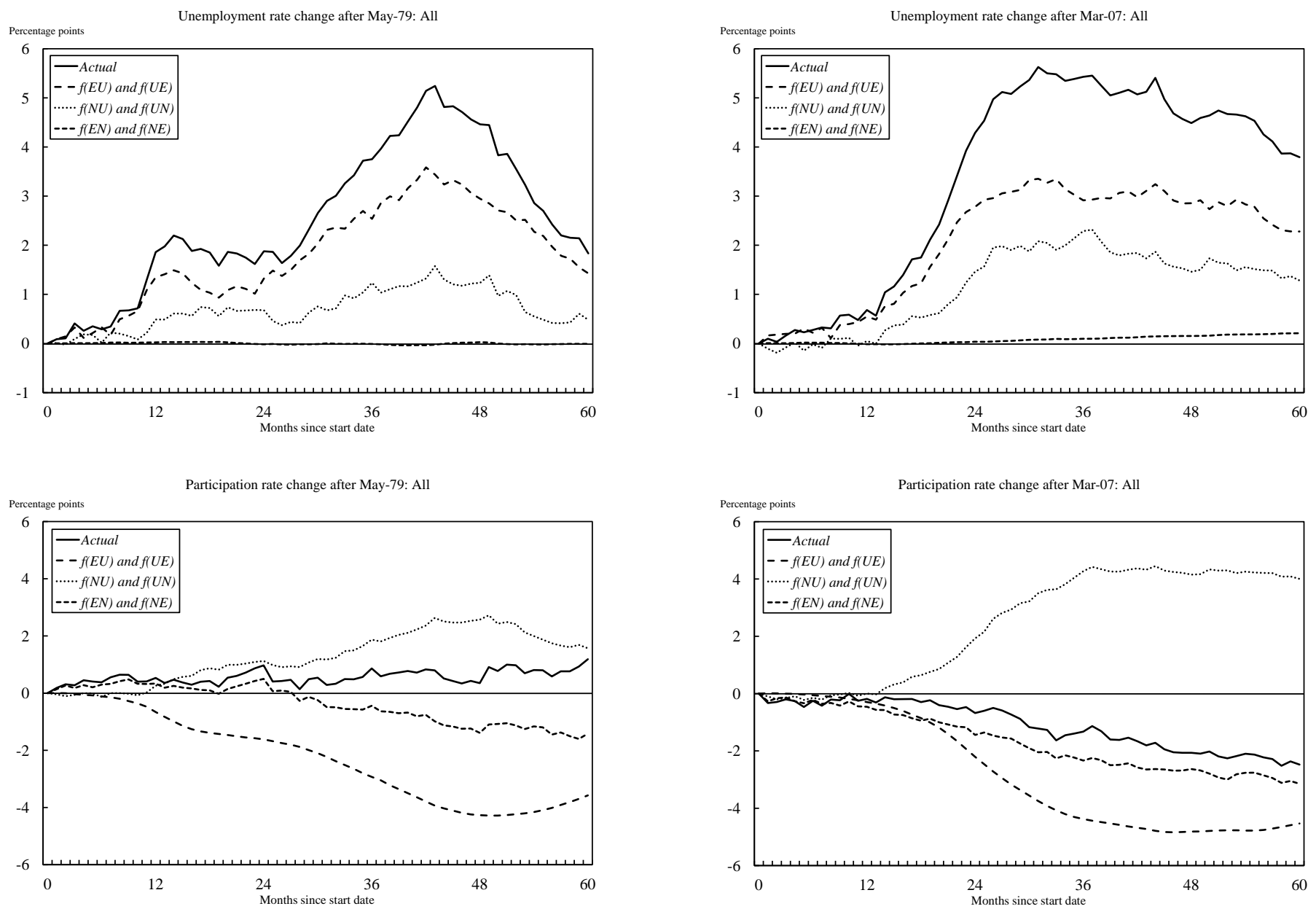
Figure 5: Nonparticipation-to-unemployment flow probabilities for men and women by age
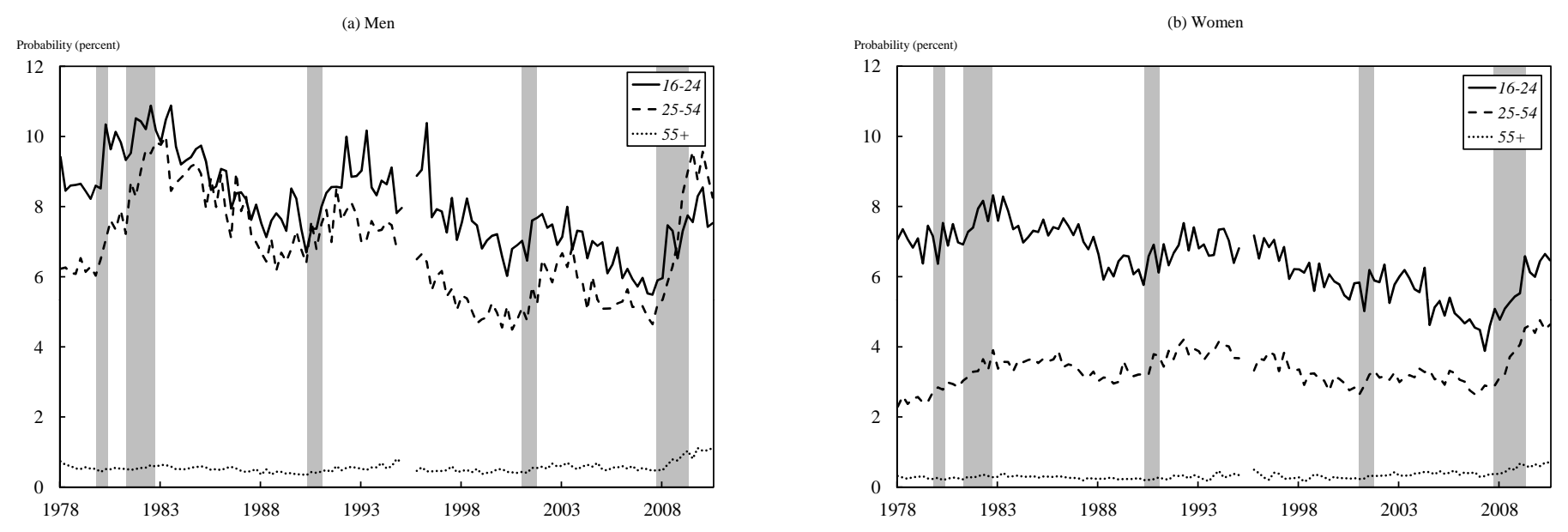


\section{A Mathematical details}

\section{A.1 Derivation of equation (4)}

Given the classification errors in equation (1), and under the assumption that $\varepsilon_{i j}=0$ for all $i j \notin\{U N, N U\}$, measured flows between unemployment and nonparticipation can be written as

$$
\begin{aligned}
U N_{t} & =\varepsilon_{U U}\left[\varepsilon_{U N} U U_{t}^{*}+\varepsilon_{N N} U N_{t}^{*}\right]+\varepsilon_{N U}\left[\varepsilon_{U N} N U_{t}^{*}+\varepsilon_{N N} N N_{t}^{*}\right], \text { and } \\
N U_{t} & =\varepsilon_{U N}\left[\varepsilon_{U U} U U_{t}^{*}+\varepsilon_{N U} U N_{t}^{*}\right]+\varepsilon_{N N}\left[\varepsilon_{U U} N U_{t}^{*}+\varepsilon_{N U} N N_{t}^{*}\right] .
\end{aligned}
$$

Noting that $\varepsilon_{U U}=1-\varepsilon_{U N}, \varepsilon_{N N}=1-\varepsilon_{N U}$, and that any product of the errors is second order in the presence of small $\varepsilon_{U N}$ and $\varepsilon_{N U}$ yields the approximation in equation (4).

\section{A.2 Margin-error adjustment}

We use the following method to adjust the transition probabilities that we get from the data to make them consistent with the labor market status vector, $\mathbf{s}_{t}$. Note that

$$
\begin{aligned}
\Delta \mathbf{s}_{t} & =\mathbf{s}_{t}-\mathbf{s}_{t-1}=\left[\begin{array}{ccccc}
-p_{E U}-p_{E N} & p_{U E} & p_{N E} \\
p_{E U} & -p_{U E}-p_{U N} & p_{N U}
\end{array}\right]\left[\begin{array}{c}
E_{t-1} \\
U_{t-1} \\
N_{t-1}
\end{array}\right] \\
& =\left[\begin{array}{cccccc}
-E_{t-1} & -E_{t-1} & U_{t-1} & 0 & N_{t-1} & 0 \\
E_{t-1} & 0 & -U_{t-1} & -U_{t-1} & 0 & N_{t-1}
\end{array}\right]\left[\begin{array}{c}
p_{E U} \\
p_{E N} \\
p_{U E} \\
p_{U N} \\
p_{N E} \\
p_{N U}
\end{array}\right] \\
& =\mathbf{X}_{t-1} \mathbf{p} .
\end{aligned}
$$

Note that the vector of transitional probabilities that we get from the data, which we denote by $\widehat{\mathbf{p}}$, has a covariance matrix that is proportional to a matrix that is consistently estimated using

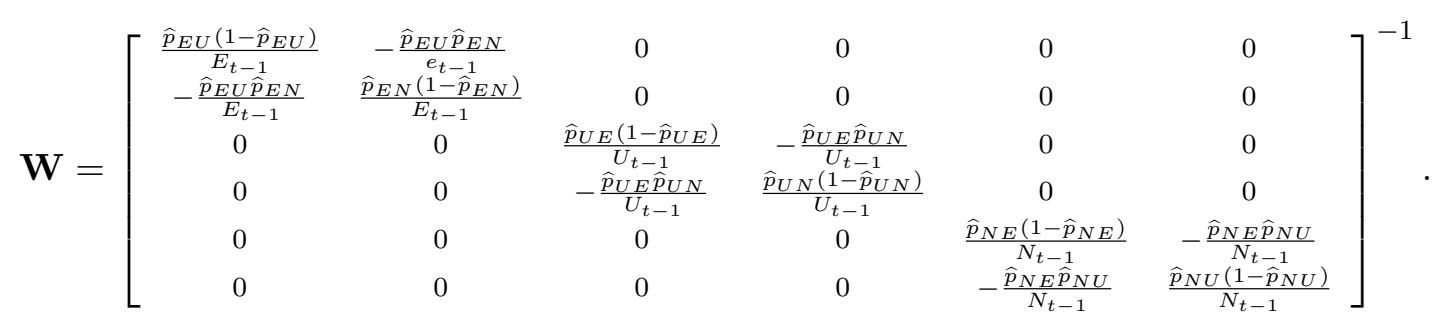

We apply a weighted-restricted-least-squares adjustment method in the sense that we choose the vector of transition probabilities that are consistent with the labor market status vector, which we denote by $\mathbf{p}$, to

$$
\operatorname{minimize}(\mathbf{p}-\widehat{\mathbf{p}})^{\prime} \mathbf{W}(\mathbf{p}-\widehat{\mathbf{p}}), \text { subject to } \Delta \mathbf{s}_{t}=\mathbf{X}_{t-1} \mathbf{p}
$$


Given the associated Lagrangian

$$
L=(\mathbf{p}-\widehat{\mathbf{p}})^{\prime} \mathbf{W}(\mathbf{p}-\widehat{\mathbf{p}})-2 \mu^{\prime}\left(\Delta \mathbf{s}_{t}-\mathbf{X}_{t-1} \mathbf{p}\right),
$$

where $\mu$ is the $2 \times 1$-vector with Lagrange multipliers, it is fairly straightforward to derive that

$$
\left[\begin{array}{l}
\mathbf{p} \\
\mu
\end{array}\right]=\left[\begin{array}{cc}
\mathbf{W} & \mathbf{X}_{t-1}^{\prime} \\
-\mathbf{X}_{t-1} & \mathbf{0}
\end{array}\right]\left[\begin{array}{c}
\mathbf{W} \widehat{\mathbf{p}} \\
\Delta \mathbf{s}_{t}
\end{array}\right] .
$$

Since all the terms on the right hand side are known, we can use this equation to adjust the transition probabilities to $\mathbf{p}$.

\section{A.3 Temporal-aggregation correction}

From equation (6), the discrete-time transition probabilities satisfy $\mathbf{s}_{t}=\widetilde{\mathbf{P}}_{t} \mathbf{s}_{t-1}+\mathbf{q}_{t}$. Similarly, from (10), the analogous continuous-time Markov chain is given by $\dot{\mathbf{s}}_{t}=\widetilde{\mathbf{F}}_{t} \mathbf{s}_{t}+\mathbf{g}_{t}$. Both of these systems imply a steady state $\overline{\mathbf{s}}_{t}$ that satisfies $\overline{\mathbf{s}}_{t}=-\widetilde{\mathbf{F}}_{t}^{-1} \mathbf{g}_{t}=-\widetilde{\mathbf{P}}_{t}^{-1} \mathbf{q}_{t}$. Let $\xi_{t}=\left(\mathbf{s}_{t}-\overline{\mathbf{s}}_{t}\right)$. Applying this transform to the discrete-time Markov chain, we can write $\xi_{t}=\widetilde{\mathbf{P}}_{t} \xi_{t-1}$. Likewise, using the continuous-time Markov chain, we can write $\dot{\xi}_{t}=\widetilde{\mathbf{F}}_{t} \xi_{t}$. The latter has solution $\xi_{t}=\mathbf{V}_{t} \boldsymbol{\Lambda}_{t} \mathbf{V}_{t}^{-1} \xi_{t-1}$, where $\mathbf{V}_{t}=\left[\overline{\mathbf{s}}_{t}, v_{1 t}, v_{2 t}\right]$ is the matrix of eigenvectors of $\widetilde{\mathbf{F}}_{t}$, and $\boldsymbol{\Lambda}=\operatorname{diag}\left\{1, e^{\lambda_{1 t}}, e^{\lambda_{2 t}}\right\}$ the matrix whose diagonal elements are the associated eigenvalues of $\widetilde{\mathbf{F}}_{t}$. It follows that the discrete-time transition matrix is given by $\widetilde{\mathbf{P}}_{t}=\mathbf{V}_{t} \boldsymbol{\Lambda}_{t} \mathbf{V}_{\mathbf{t}}^{-\mathbf{1}}$. The latter implies that the eigenvectors of $\widetilde{\mathbf{P}}_{t}$ are the same as those of $\widetilde{\mathbf{F}}_{t}$, and that the eigenvalues of $\widetilde{\mathbf{P}}_{t}$ are equal to the exponentiated eigenvalues of $\widetilde{\mathbf{F}}_{t}$. Hence, given an estimate of $\widetilde{\mathbf{P}}_{t}$, one can infer the matrix of flow hazard rates $\widetilde{\mathbf{F}}_{t}$ via the above eigendecomposition.

\section{A.4 Derivation of equation (7)}

Note first that one can decompose the change in labor market state into parts,

$$
\Delta \mathbf{s}_{t}=\left(\mathbf{s}_{t}-\overline{\mathbf{s}}_{t}\right)-\left(\mathbf{s}_{t-1}-\overline{\mathbf{s}}_{t-1}\right)+\Delta \overline{\mathbf{s}}_{t} .
$$

Then note that the reduced Markov chain $\mathbf{s}_{t}=\widetilde{\mathbf{P}}_{t} \mathbf{s}_{t-1}+\mathbf{q}_{t}$ can be written as:

$$
\left(\mathbf{s}_{t}-\overline{\mathbf{s}}_{t}\right)=\widetilde{\mathbf{P}}_{t}\left(\mathbf{s}_{t-1}-\overline{\mathbf{s}}_{t}\right)=\widetilde{\mathbf{P}}_{t}\left(\mathbf{s}_{t-1}-\overline{\mathbf{s}}_{t-1}\right)-\widetilde{\mathbf{P}}_{t} \Delta \overline{\mathbf{s}}_{t}
$$

Substituting for $\left(\mathbf{s}_{t}-\overline{\mathbf{s}}_{t}\right)$ in $(22)$ implies:

$$
\Delta \mathbf{s}_{t}=-\left(\mathbf{I}-\widetilde{\mathbf{P}}_{t}\right)\left(\mathbf{s}_{t-1}-\overline{\mathbf{s}}_{t-1}\right)+\left(\mathbf{I}-\widetilde{\mathbf{P}}_{t}\right) \Delta \overline{\mathbf{s}}_{t}
$$

Similarly, noting from (23) that $\left(\mathbf{s}_{t-1}-\overline{\mathbf{s}}_{t-1}\right)-\Delta \overline{\mathbf{s}}_{t}=\widetilde{\mathbf{P}}_{t}^{-1}\left(\mathbf{s}_{t}-\overline{\mathbf{s}}_{t}\right)$ implies that (22) can be rewritten as

$$
\Delta \mathbf{s}_{t}=\left(\widetilde{\mathbf{P}}_{t}-\mathbf{I}\right) \widetilde{\mathbf{P}}_{t}^{-1}\left(\mathbf{s}_{t}-\overline{\mathbf{s}}_{t}\right)
$$

Combining the latter with (24) confirms the proposed solution. 